\title{
Mixing, Domains, and Fast Li-ion Dynamics in Ternary Li-Sb-Bi Battery Anode Alloys
}

W. Peter Kalisvaart,* Madhusudan Chaudhary, Amit Bhattacharya, Vladimir K. Michaelis*, Jillian M. Buriak*

Department of Chemistry, University of Alberta, 11227 Saskatchewan Drive, Edmonton, AB T6G 2G2, Canada

*Corresponding authors. Email addresses:

pkalisva@ualberta.ca (W. Peter Kalisvaart), vmichael@ualberta.ca (Vladimir K. Michaelis), jburiak@ualberta.ca (Jillian M. Buriak) 


\begin{abstract}
Antimony and bismuth can both alloy with up to three molar equivalents of lithium and are therefore attractive candidates for replacing graphite in $\mathrm{Li}$-ion battery anodes. $\mathrm{Li}_{3} \mathrm{Sb}$ and $\mathrm{Li}_{3} \mathrm{Bi}$ have the same cubic structure $(F m \overline{3} m)$, but the ternary Li-Sb-Bi system has not been studied. We synthesized $\mathrm{Li}_{3}\left(\mathrm{Sb}_{\mathrm{x}} \mathrm{Bi}_{1-\mathrm{x}}\right)$ with different $\mathrm{Sb}$ mole fractions at room temperature by ball-milling. These ternary alloys all have cubic crystal structures, as determined by XRD, but show a tendency towards phase segregation for $\mathrm{x}=0.25$ and 0.50 . For $\mathrm{x}=0.25$, the lattice parameter presents a clear positive deviation from Vegard's law in XRD, while for $\mathrm{x}=0.50, \mathrm{XRD}$ reveals two phases after milling, with the Bi-rich minority phase diminishing after thermal annealing. Solid-state nuclear magnetic resonance spectroscopy provides evidence for a Sb-enriched environment around the $\mathrm{Li}$ atoms for $\mathrm{Li}_{3} \mathrm{Sb}_{0.25} \mathrm{Bi}_{0.75}$, and nuclear spin-lattice relaxation measurements of the binary and ternary alloy phases point to low activation energies and rapid Li ion diffusion in $\mathrm{Li}_{3} \mathrm{Bi}$.
\end{abstract}

\title{
Keywords
}

Lithium-ion batteries, Anodes, Solid-state NMR, Dynamics, Mechanochemical synthesis 


\section{INTRODUCTION}

Antimony and its alloys have been intensively studied in recent years as high-capacity anode materials in alkali metal-ion based rechargeable batteries. ${ }^{1-10}$ It has a theoretical storage capacity of $660 \mathrm{mAh} / \mathrm{g}$, which is almost twice as high as graphite $(372 \mathrm{mAh} / \mathrm{g})$ that is currently used in commercial lithium-ion batteries (LIB), and double that of hard carbon in emerging sodium-ion batteries. ${ }^{11-13}$ Recently, antimony-based anodes have been extended to include potassium-ion batteries. ${ }^{14,15}$ The range of antimony-alkali compounds that has been characterized is, however, considerably broader than just these two elements, and can include up to three alkali metal ions from group I, from lithium to cesium, with the number of intermediate compounds increasing as one moves down the group of the periodic table. ${ }^{16,17}$ In contrast to the more widely studied tin anodes, antimony shows good performance in conventional commercial carbonate-based electrolytes, making it a more suitable candidate to replace graphite in LIBs. ${ }^{18-20}$

Bismuth is isostructural with antimony and the elements have full mutual solid solubility above $200{ }^{\circ} \mathrm{C} .{ }^{17}$ However, thermodynamic calculations suggest there is a miscibility gap below $140{ }^{\circ} \mathrm{C} .{ }^{21}$ Like antimony, bismuth also alloys with up to three molar equivalents of alkali metals from lithium to cesium. ${ }^{16,17}$ Since bismuth is much more ductile than antimony, it makes the material less susceptible to fracture during electrochemical cycling with lithium, and there are several examples of bismuth addition to antimony improving the cycling stability relative to either element by itself., ${ }^{2,8}$ Although in-situ diffraction data of the individual elements during lithiation are available and show that $\mathrm{A}_{3} \mathrm{Bi}$ and $\mathrm{A}_{3} \mathrm{Sb}(\mathrm{A}=\mathrm{Li}, \mathrm{Na}, \mathrm{K})$ are isostructural, ${ }^{15,22-}$ ${ }^{25}$ no such data exist on binary $\mathrm{Sb}$-Bi solid solutions. In addition, no ternary phase diagrams obtained via metallurgical routes have been reported. ${ }^{17}$

Solid-state nuclear magnetic resonance (NMR) spectroscopy is a highly sensitive method to interrogate local atomic chemical environments and is therefore suitable to study subtle compositional variations on short length scales $(<10 \AA)$ in a multicomponent alloy. Such socalled 'incipient' phase segregation can be detected by NMR more readily than by other techniques that represent an average long-range crystalline structure, as is the case for X-ray diffraction (XRD). ${ }^{26-31}$ The lithiation potential of antimony is approximately $200 \mathrm{mV}$ more positive than that of bismuth, ${ }^{8}$ indicating higher thermodynamic stability, which could result in the formation of Sb-rich clusters. Therefore, diffraction and NMR methods are complementary techniques that, together, provide a detailed and nuanced view of a material's structure. NMR also provides insightful information about dynamics, and the onset of ion dynamics within 
conductive materials, which is important information with regards to battery applications, and in particular rate-capability. ${ }^{32-41}$

In the present work, we study a series of ternary $\mathrm{Li}_{3} \mathrm{Sb}_{\mathrm{x}} \mathrm{Bi}_{1-\mathrm{x}}$ compounds using $\mathrm{XRD}$ and NMR spectroscopy. The Li-rich alloys were synthesized using thermal annealing, ball milling, or a combination thereof, rather than electrochemical lithiation in order to more accurately control the Li-to-metal stoichiometry and eliminate any quantitative errors or additional NMR signals from Li salts formed by electrolyte decomposition. ${ }^{39,42}$ Antimony and bismuth show close-toideal solid solution behavior in binary alloys. Ternary $\mathrm{Li}_{3} \mathrm{Sb}_{\mathrm{x}} \mathrm{Bi}_{1-\mathrm{x}}$ alloys show evidence of phase segregation for $\mathrm{x}=0.25$ and 0.50 (prior to annealing). A minority phase that is enriched in $\mathrm{Sb}$ is detected by NMR for $x=0.25$. Our findings provide future directions for in-situ and operando diffraction experiments tracking phase transformations during lithiation of these binary metal SbBi alloys.

\section{EXPERIMENTAL SECTION}

Antimony and bismuth metal powders were purchased from SigmaAldrich (St. Louis, MO). Lithium foil was obtained from MTI Corporation (Richmond, CA).

The Sb-Bi solid solutions with compositions $\mathrm{Sb}_{0.25} \mathrm{Bi}_{0.75}, \mathrm{Sb}_{0.50} \mathrm{Bi}_{0.50}$ and $\mathrm{Sb}_{0.75} \mathrm{Bi}_{0.25}$ were prepared as starting materials by melt spinning followed by annealing. Melt spinning was performed on an Edmund Buehler GMBH SC10 single-roller melt spinner. Compacted powder pellets of the desired overall composition were loaded into a BN crucible and induction melted using a $5 \mathrm{~kW}$ HU5 RF generator. The melting process was monitored using a pyrometer. The melt was ejected at a temperature of $700-750{ }^{\circ} \mathrm{C}$ onto a $30 \mathrm{~cm}$ diameter copper wheel spinning at $40 \mathrm{~Hz}$, corresponding to a surface velocity of $38 \mathrm{~m} / \mathrm{s}$. The resulting materials were not yet singlephase and were crushed in an agate mortar, milled for 30 minutes using 304 stainless steel milling tools at $500 \mathrm{rpm}$ and annealed on a hotplate. The annealing temperature was set to the solidus temperature for that particular composition, ranging from $300{ }^{\circ} \mathrm{C}$ for $\mathrm{Sb}_{0.25} \mathrm{Bi}_{0.75}$ to $380{ }^{\circ} \mathrm{C}$ for $\mathrm{Sb}_{0.75} \mathrm{Bi}_{0.25}$, for 16 hours, under argon.

Lithiation was performed at room temperature, as it would be in a battery, by ball milling the powders with a stoichiometric amount of Li foil for 5 hours at $500 \mathrm{rpm}$ on a TenCan XQM-2 planetary mill using $50 \mathrm{ml} 304$ stainless steel jars and balls. The Sb-Bi starting alloys were processed in $2 \mathrm{~g}$ batches using $20 \mathrm{~g}$ of balls. Reactants were weighed inside the glovebox on a Mettler Toledo balance with $1 \mathrm{mg}$ readability. Elemental Bi turned out to be too ductile to be milled effectively with $\mathrm{Li}$. To synthesize $\mathrm{Li}_{3} \mathrm{Bi}$, a pressed pellet of $\mathrm{Bi}$ powder was wrapped in a 
stoichiometric amount of $\mathrm{Li}$ foil and fired on a hotplate set at $300{ }^{\circ} \mathrm{C}$ for $16 \mathrm{~h}$ in an alumina crucible covered with a quartz glass plate inside an Ar-filled glovebox.

Powder XRD was performed on an Ultima IV multipurpose diffractometer (Rigaku) with a $285 \mathrm{~mm}$ goniometer radius or on an AXS diffractometer (Discover 8, Bruker, Madison, WI) with $\mathrm{Cu} \mathrm{K} \alpha$ radiation $(\lambda=1.5406 \AA$ ). The AXS diffractometer was equipped with a twodimensional general-area diffraction detection system (GADDs) using a Vantec-500 detector with a sample-detector distance of $22 \mathrm{~cm}$. To protect the lithiated materials from air and moisture, double-sided adhesive Kapton tape with a round cutout was laminated onto a glass slide. The powder was added into the compartment left by the cutout and then covered with a polypropylene foil, all while handling the powder under an inert Ar atmosphere. A photo of the resulting window is included as Figure S1.

Solid-state NMR experiments were performed on a Bruker $500 \mathrm{MHz}\left(\mathrm{B}_{0}=11.75 \mathrm{~T}\right)$ Avance NEO NMR spectrometer, equipped with a $4 \mathrm{~mm}$ double resonance HX magic-angle spinning (MAS) Bruker probe. Powdered samples were diluted (50\% by mass with dry silica) and packed into $4 \mathrm{~mm}$ o.d. zirconia ceramic rotors and sealed with a Vespe ${ }^{\circledR}$ cap inside an $\operatorname{Ar}$ glove box. ${ }^{7}$ Li MAS NMR data were acquired using a Bloch decay pulse sequence with optimized pulse widths between 3.3 and $4.0 \mu$ s (calibrated for each sample, $\gamma_{1} B_{1} / 2 \pi=71 \mathrm{kHz}$ (solution)), recycle delays of 5-20 s, 16 co-added transients and a spinning frequency of $10 \mathrm{kHz}$. Variable temperature non-spinning ${ }^{7} \mathrm{Li}$ NMR using a Bloch decay and inversion recovery pulse sequences were used to measure the linewidth (fwhm) and nuclear spin-lattice relaxation $\left(T_{1}\right)$, respectively, between 203 and $333 \mathrm{~K}$. Acquisition parameters were identical to those reported above. The ${ }^{7} \mathrm{Li}$ NMR spectra were referenced to $0 \mathrm{ppm}$ using $1 \mathrm{M} \mathrm{LiCl}$ solution. Non-spinning ${ }^{121} \mathrm{Sb} \mathrm{NMR}$ measurements were acquired using a Hahn echo $(\pi / 2-\tau-\pi-$ acq. $)$ pulse sequence, with 2 and $4 \mu \mathrm{s}$ pulses ( $\mathrm{\gamma B}_{1} / 2 \pi=42 \mathrm{kHz}$ (solution)), between $2 \mathrm{k}$ and $100 \mathrm{k}$ co-added transients and recycle delays of $0.25-1 \mathrm{~s}$. For ${ }^{121} \mathrm{Sb}$ NMR spectra of $\mathrm{Li}_{2} \mathrm{Sb}$ and $\mathrm{Li}_{3} \mathrm{Sb}_{\mathrm{x}} \mathrm{Bi}_{1-\mathrm{x}}$ compounds the variable offset cumulative spectrum (VOCS) ${ }^{43}$ approach was applied using 50-100 kHz offsets and between 3 and 10 steps. The ${ }^{121} \mathrm{Sb}$ NMR spectra were referenced to $0 \mathrm{ppm}$ using $0.5 \mathrm{M} \mathrm{KSbF}_{6}$ in acetonitrile. The non-spinning ${ }^{209} \mathrm{Bi}$ NMR spectrum of $\mathrm{Li}_{3} \mathrm{Bi}$ was collected using a Bloch decay pulse sequence with a $\pi / 2=3.2 \mu \mathrm{s}, 128$ co-added transients and a $1 \mathrm{~s}$ recycle delay. The ${ }^{209} \mathrm{Bi}$ NMR data was referenced to 0 ppm using a saturated solution of $\mathrm{Bi}\left(\mathrm{NO}_{3}\right)_{3}$ in $\mathrm{HNO}_{3}$ and $\mathrm{D}_{2} \mathrm{O}$. 


\section{RESULTS AND DISCUSSION}

\section{Preparation of $\mathrm{Sb}_{\mathbf{x}} \mathrm{Bi}_{1-\mathrm{x}}$ solid solutions}

Powder XRD patterns of the $\mathrm{Sb}_{\mathrm{x}} \mathrm{Bi}_{1-\mathrm{x}}$ alloys in the as-prepared and annealed states are shown in

Figure 1 . The unlithiated starting alloys were prepared via melt spinning followed by thermal annealing. The cooling rate during melt spinning is insufficient to cross the liquidus-solidus gap vertically and produce a single-phase material, which is why a subsequent annealing step is required to form a single-phase compound. As illustrated on the right-hand side in Figure 1, all $\mathrm{XRD}$ patterns are shifted towards lower angles, i.e. larger d-spacing, as the Bi content is increased, which is expected based on the larger atomic radius (148 pm (Bi) vs $139 \mathrm{pm}(\mathrm{Sb}))$ of this element. Although thermodynamic calculations point to the possible existence of a miscibility gap below $140{ }^{\circ} \mathrm{C},{ }^{21}$ experimental evidence for this gap is difficult to interrogate experimentally as solid-state diffusion is very slow at these low temperatures. Although the samples described here were not 'quenched' in any way after the annealing step, there is no evidence for phase separation and complete solid solubility appears to be achieved. As an additional illustration, the XRD patterns in Figure S2 show a narrower angular range where the peak positions for all three compositions fall between the $\mathrm{Sb}$ and Bi reference patterns. The unit cell volumes obtained from refinement of the diffraction patterns support a linear relationship between the unit cell volume and $\mathrm{x}_{\mathrm{Sb}}\left(\mathrm{R}^{2}=0.99\right)$, as shown in Figure $\mathrm{S} 3$, indicating ideal solidsolution behavior in the binary $\mathrm{Sb}-\mathrm{Bi}$ host materials.

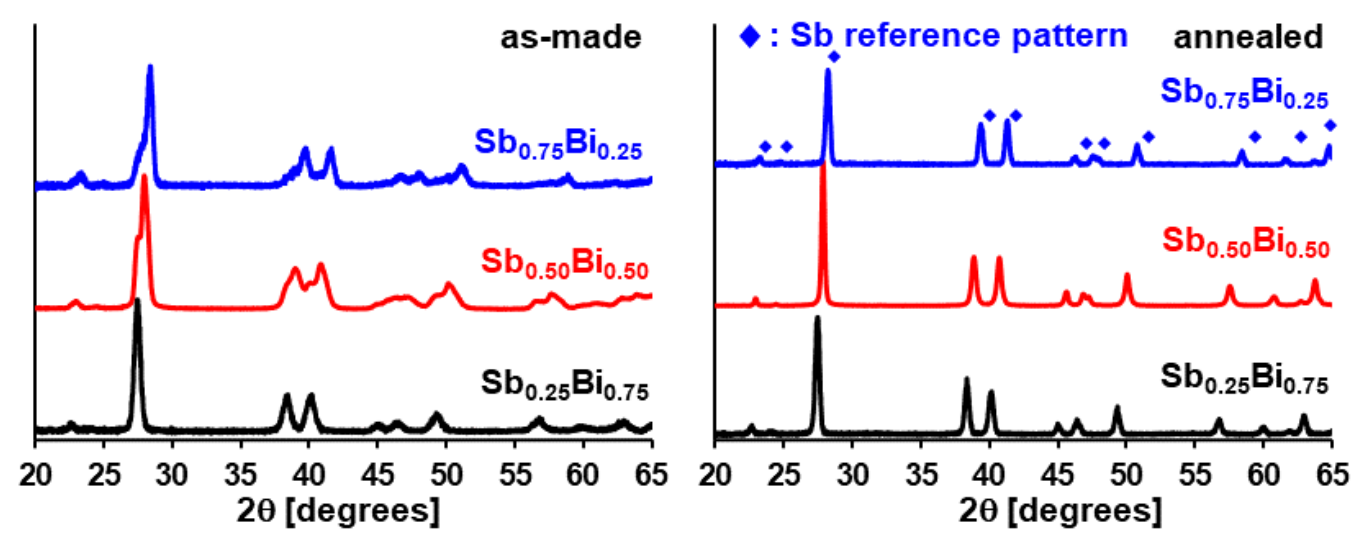

Figure 1. Powder $\mathrm{XRD}$ patterns of as-made $\mathrm{Sb}_{\mathrm{x}} \mathrm{Bi}_{1-\mathrm{x}}$ alloys after melt spinning (left) and after milling and annealing (right). The theoretical peak positions of Sb metal are marked by the blue diamonds to illustrate the shifts of the peaks with composition. 


\section{$\mathbf{L i}_{3}\left(\mathrm{Sb}_{\mathbf{x}} \mathrm{Bi}_{1-\mathrm{x}}\right)$ alloy preparation}

The lithiated alloys were synthesized by taking the $\mathrm{Sb}_{\mathrm{x}} \mathrm{Bi}_{1-\mathrm{x}}$ alloys, prepared via melt-spinning, ball milling and annealing, and then ball-milling them with $\mathrm{Li}$ metal. To synthesize $\mathrm{Li}_{3} \mathrm{Bi}$, a Bi pellet was wrapped in $\mathrm{Li}$ foil and fired at $300{ }^{\circ} \mathrm{C}$, because all the material was observed to stick to the milling balls and vial when ball milling was attempted. The powder XRD patterns for the $\mathrm{Li}_{3}\left(\mathrm{Sb}_{\mathrm{x}} \mathrm{Bi}_{1-\mathrm{x}}\right)$ are shown in Figure 2. The lattice parameters, grain size and microstrain are summarized in Table 1 . As is the case for the metals, $\mathrm{Li}_{3} \mathrm{Bi}$ has a larger lattice parameter and unit cell volume than $\mathrm{Li}_{3} \mathrm{Sb}$ and the peak positions of the intermediate compositions are clearly shifted from $\mathrm{Li}_{3} \mathrm{Sb}$ towards $\mathrm{Li}_{3} \mathrm{Bi}$ as the $\mathrm{Bi}$ content increases. For all compositions, it appears that a single-phase, face-centered-cubic (fcc) compound can be formed. 


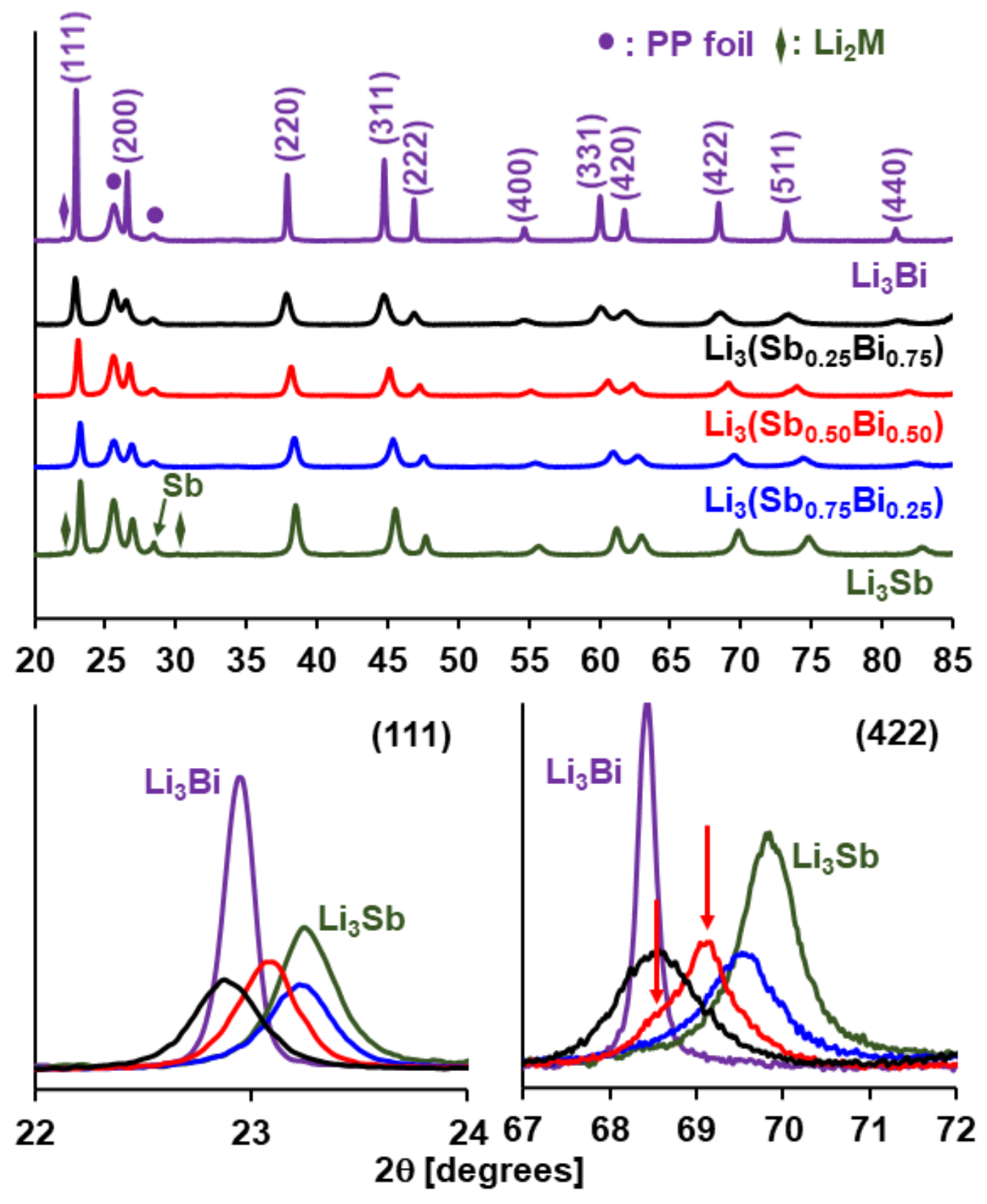

Figure 2. Powder XRD patterns of $\mathrm{Li}_{3}\left(\mathrm{Sb}_{\mathrm{x}} \mathrm{Bi}_{1-\mathrm{x}}\right)$ alloys. Trace amounts of $\mathrm{Sb}$ metal (arrow), $\mathrm{Li}_{2} \mathrm{Sb}$ and $\mathrm{Li}_{2} \mathrm{Bi}$ (diamonds) are marked, as well as the largest peaks from the protective polypropylene foil (dots in the $\mathrm{Li}_{3} \mathrm{Bi}$ pattern). The bottom two panels show magnifications of the (111) and (422) peaks of the fcc phase and illustrate the increase in unit cell volume with increasing Bi content as well as the presence of secondary phase(s) in $\mathrm{Li}_{3}\left(\mathrm{Sb}_{0.50} \mathrm{Bi}_{0.50}\right)$.

$\mathrm{Li}_{3} \mathrm{Sb}$ is formed during the milling step between $\mathrm{Sb}$ powder and Li metal. The sample contains traces of $\mathrm{Sb}$ metal and $\mathrm{Li}_{2} \mathrm{Sb}$, as confirmed by NMR (vide infra), indicating a slight under-stoichiometry due to weighing errors or selective cold welding of Li to the milling tools due to its ductility. The lattice parameter of $\mathrm{Li}_{3} \mathrm{Sb}$ appears to be slightly larger than that found in 
the literature, 6.58 vs. $6.56 \AA$, even though $\mathrm{Li}_{3} \mathrm{Sb}$ is considered to be a line compound. ${ }^{17} \mathrm{Li}_{3} \mathrm{Bi}$ has the largest grain size and lowest microstrain, which is not surprising since it is the only one in the series to have been synthesized by thermal annealing rather than ball milling. Although most LiBi phase diagrams found in the literature do not list this phase, its existence has been confirmed by Pavlyuk et al. using XRD. It is isostructural with $\mathrm{Li}_{2} \mathrm{Sb}$ and disproportionates into $\mathrm{LiBi}$ and $\mathrm{Li}_{3} \mathrm{Bi}$ above $200{ }^{\circ} \mathrm{C}^{44} \mathrm{Li}_{3}\left(\mathrm{Sb}_{0.75} \mathrm{Bi}_{0.25}\right)$ and $\mathrm{Li}_{3}\left(\mathrm{Sb}_{0.25} \mathrm{Bi}_{0.75}\right)$ appear to be single-phase after ball milling with a lattice constant that is clearly shifted to higher values with respect to $\mathrm{Li}_{3} \mathrm{Sb}$. However, refinement of the diffraction data indicates that the lattice constant for $\mathrm{Li}_{3}\left(\mathrm{Sb}_{0.25} \mathrm{Bi}_{0.75}\right)$ is shifted much closer to that of $\mathrm{Li}_{3} \mathrm{Bi}$ than expected based on the nominal composition, which is already somewhat obvious from the position of the (111) peak in Figure 2. The lattice parameters, grain size, and microstrain are summarized in Table 1. The change in lattice parameter and unit cell volume between $\mathrm{Li}_{3} \mathrm{Bi}$ and $\mathrm{Li}_{3} \mathrm{Sb}_{0.25} \mathrm{Bi}_{0.75}$ are significantly smaller than for any subsequent step in the composition. Because the binary Sb-Bi did not show any deviations from ideal solid solution behavior, the anomalous values of the unit cell volume for $\mathrm{x}=0.25$ are a direct result of the lithiation step.

Table 1. Lattice parameters, unit cell volume, grain size and micro-strain of $\mathrm{Li}_{3} \mathrm{Sb}_{\mathbf{x}} \mathrm{Bi}_{1-\mathrm{x}}$ alloys.

\begin{tabular}{lllll} 
Compound & $\begin{array}{l}\text { Lattice } \\
\text { parameter } a(\AA)\end{array}$ & $\begin{array}{l}\text { Unit cell volume } \\
V\left(\AA^{3}\right)\end{array}$ & $\begin{array}{l}\text { Average grain } \\
\text { size }(\mathrm{nm})\end{array}$ & $\begin{array}{l}\text { Maximum micro- } \\
\text { strain }(\%)\end{array}$ \\
$\mathrm{Li}_{3} \mathrm{Bi}$ & $6.7129(1)$ & $302.50(1)$ & Micron size & 0.16 \\
$\mathrm{Li}_{3} \mathrm{Sb}_{0.25} \mathrm{Bi}_{0.75}$ & $6.6971(3)$ & $300.37(3)$ & 49 & 1.06 \\
$\mathrm{Li}_{3} \mathrm{Sb}_{0.5} \mathrm{Bi}_{0.5} *$ & $6.6534(2)$ & $294.54(1)$ & 58 & 0.66 \\
$\mathrm{Li}_{3} \mathrm{Sb}_{0.75} \mathrm{Bi}_{0.25}$ & $6.6196(3)$ & $290.07(2)$ & 67 & 0.99 \\
$\mathrm{Li}_{3} \mathrm{Sb}$ & $6.5827(2)$ & $285.24(1)$ & 54 & 0.58 \\
\multicolumn{5}{r}{ *: contains Li $\mathrm{Li}_{3} \mathrm{Bi}$ minority phase }
\end{tabular}

For $\mathrm{Li}_{3}\left(\mathrm{Sb}_{0.50} \mathrm{Bi}_{0.50}\right)$, the pattern depicted in Figure 2 is that of the material after annealing at $350{ }^{\circ} \mathrm{C}$ for 16 hours. As shown in Figure S4, the as-milled material clearly consists of multiple fcc phases. At higher angles in particular, the peaks are very wide and appear to be composed of at least two separate peaks. Annealing narrows all the peaks considerably, indicative of grain growth, and the peaks of any secondary fcc phases clearly diminish in intensity. As highlighted in the inset of Figure 2 showing the (422) peaks, a small shoulder is still visible on the low-angle side for $\mathrm{Li}_{3}\left(\mathrm{Sb}_{0.50} \mathrm{Bi}_{0.50}\right)$, but not for any of the other compositions. The lattice parameter of the secondary phase is close to that of $\mathrm{Li}_{3} \mathrm{Bi}$. When attempting to synthesize ternary alloys at a higher temperature $\left(400^{\circ} \mathrm{C}\right)$, disproportionation of the material and segregation of high-temperature (hexagonal) $\mathrm{Li}_{3} \mathrm{Sb}$ were observed as shown in Figure $\mathrm{S} 5$ for $\mathrm{Li}_{3}\left(\mathrm{Sb}_{0.25} \mathrm{Bi}_{0.75}\right)$. 
Therefore, $350{ }^{\circ} \mathrm{C}$ is probably close to the limit that these materials can withstand before decomposing into the respective binary compounds.

From the diffraction data, it appears that at $3 \mathrm{Li} /(\mathrm{Sb}+\mathrm{Bi})$, a single phase fcc material is thermodynamically favored for the full compositional range, although for $\mathrm{x}=0.50$, an annealing step was necessary. It is important to consider whether this behavior would be representative of electrochemical cycling. Darwiche et al. suggested, based on the voltage profile of Sb during lithiation that none of the intermediate phases on the equilibrium $\mathrm{Li}-\mathrm{Sb}$ phase diagram $\left(\mathrm{LiSb}_{2}\right.$, $\mathrm{Li}_{3} \mathrm{Sb}_{2}$ and $\mathrm{Li}_{2} \mathrm{Sb}$ ) are formed and that $\mathrm{Li}_{3} \mathrm{Sb}$ immediately forms instead. ${ }^{22}$ However, this claim contradicts the findings from in-situ XRD by Hewitt et al., where $\mathrm{Li}_{2} \mathrm{Sb}$ was observed. ${ }^{24}$ Operando NMR measurements have also confirmed the formation of $\mathrm{Li}_{2} \mathrm{Sb}$ during lithiation. ${ }^{39,42}$ When we attempted to synthesize pure $\mathrm{Li}_{2} \mathrm{Sb}$ by ball milling, the as-milled powder consisted of $\mathrm{Sb}$ metal, cubic $\mathrm{Li}_{3} \mathrm{Sb}$, and only a trace amount of $\mathrm{Li}_{2} \mathrm{Sb}$ (see Figure S6). Incidentally, we observed that this phenomenon is not confined to the $\mathrm{Li}-\mathrm{Sb}$ system $-\mathrm{Li}_{15} \mathrm{Si}_{4}$ is formed when a Li-Si mixture is milled as well, as per Figure S7. Directly contacting Li metal and Sb is equivalent to short-circuiting a half-cell battery and setting the working electrode potential to $0 \mathrm{~V}$ vs. $\mathrm{Li}$. As a result, the most concentrated lithiated phase is formed first and $\mathrm{Li}_{2} \mathrm{Sb}$ is obtained only after annealing, as shown in Figure $\mathrm{S} 6$ and Figure $\mathrm{S} 8$. When the $\mathrm{Sb}_{\mathrm{x}} \mathrm{Bi}_{1-\mathrm{x}}$ solid solutions are being milled with $\mathrm{Li}$ metal, the powder mixtures most likely consist of $\mathrm{Li}$ metal, $\mathrm{Sb}_{\mathrm{x}} \mathrm{Bi}_{1-\mathrm{x}}$ solid solution, and $\mathrm{Li}_{3} \mathrm{Sb}_{\mathrm{x}} \mathrm{Bi}_{1-\mathrm{x}}$, where $\mathrm{Li}$ and $\mathrm{Sb}_{\mathrm{x}} \mathrm{Bi}_{1-\mathrm{x}}$ directly react to $\mathrm{Li}_{3} \mathrm{Sb}_{\mathrm{x}} \mathrm{Bi}_{1-\mathrm{x}}$ without forming any intermediate phases, which is different from the reaction mechanism during electrochemical cycling observed by Hewitt et al., ${ }^{24}$ but similar to that observed by Darwiche et al. ${ }^{22}$ At present, however, no in-situ or operando diffraction studies exist for these ternary compounds.

Electrochemical data from Zhao et al. ${ }^{8}$ show a broad sloping lithiation voltage plateau for binary $\mathrm{Sb}-\mathrm{Bi}$ solid solutions, indicating there are no intermediate crystalline compounds formed, and instead point to a continuous solid solution behavior of $\mathrm{Li}$ inside the host.

\section{Solid-state NMR spectroscopy}

The diffraction analysis shows that crystalline, single-phase materials are formed through mechanochemical means across the compositional range, with the exception of $\mathrm{Li}_{3} \mathrm{Sb}_{0.50} \mathrm{Bi}_{0.50}$, which showed clear signs of phase separation that could not be entirely eliminated by annealing (see Figure S4). Though the diffraction method is an excellent tool to assess the average longrange structure of crystalline solids, it is insensitive to short-range variations in composition and/or lattice spacings, reported for several metal-hydrogen systems. ${ }^{31}$ Furthermore, light elements such as lithium are harder to detect accurately using XRD because of their low number 
of electrons. However, NMR spectroscopy is sensitive to both structure (short and medium range) and dynamics in Li-containing materials; therefore, we used NMR spectroscopy to probe both the local chemical structure of $\mathrm{Sb} / \mathrm{Bi}$ mixing and $\mathrm{Li}$-ion dynamics in these $\mathrm{Li}_{3} \mathrm{Sb}_{\mathrm{x}} \mathrm{Bi}_{1-\mathrm{x}}$ ternary alloys.

Lithium-7 $(I=3 / 2)$ is an attractive nucleus for NMR spectroscopy due to its high receptivity $(92.4 \%$ N.A. and $\Xi=38.9 \%)$ and extremely small quadrupole moment $(Q=-4.01$ $\mathrm{fm}^{2}$ ). These physical properties for ${ }^{7} \mathrm{Li}$ result in it behaving as a pseudo-nuclear spin- $1 / 2 \mathrm{NMR}$ nucleus, contributing insignificantly to second-order quadrupolar broadening of the central transition peak. ${ }^{36}$ Figure 3 (a) shows the ${ }^{7} \mathrm{Li}$ MAS NMR spectra for the binary $\mathrm{Li}_{3} \mathrm{Sb}$ and $\mathrm{Li}{ }_{3} \mathrm{Bi}$ as well as the intermediate $\mathrm{Li}_{3} \mathrm{Sb}_{\mathrm{x}} \mathrm{Bi}_{1-\mathrm{x}}$ compositions. $\mathrm{Li}_{3} \mathrm{Bi}$ and $\mathrm{Li}_{3} \mathrm{Sb}$ have isotropic chemical shifts of $-10.5 \mathrm{ppm}$ and $-7.3 \mathrm{ppm}$, respectively, and can be fit using a single Gaussian, or for $\mathrm{Li}_{3} \mathrm{Bi}$, Lorentzian peak. Both compounds adopt a cubic crystal structure $(F m \overline{3} m)$ as per Figure 2, as expected based on available literature data. The linewidths for ${ }^{7} \mathrm{Li}$ NMR spectra are typically influenced by either a strong ${ }^{7} \mathrm{Li}-{ }^{7} \mathrm{Li}$ homonuclear dipolar coupling, local structural disorder about the $\mathrm{Li}$, or a combination of these. The relatively sharp $\mathrm{Li}_{3} \mathrm{Bi}$ resonance (fwhm $=40 \mathrm{~Hz}$ or 0.2 ppm) measured under MAS at room temperature has a Lorentzian-like lineshape supporting fast Li-ion mobility at room temperature. $\mathrm{Li}_{3} \mathrm{Sb}$ reveals a broader Gaussian-like resonance (fwhm $=$ $340 \mathrm{~Hz}, 1.8 \mathrm{ppm}$ ), which is likely associated with a higher distribution of local chemical environments that results from the mechanochemical treatment (vs. annealing performed on the $\mathrm{Li}_{3} \mathrm{Bi}$ materials). This observation is consistent with the lower crystallinity identified from the XRD data that contributes to broadening (due to distribution in chemical shift) in the ${ }^{7} \mathrm{Li}$ NMR spectrum. A low intensity site observed in the spectrum at $\sim-19 \mathrm{ppm}(\mathrm{fwhm}=740 \mathrm{~Hz})$ indicated by the cross, is attributed to $\mathrm{Li}_{2} \mathrm{Sb}$ (hexagonal structure) as a trace impurity. 

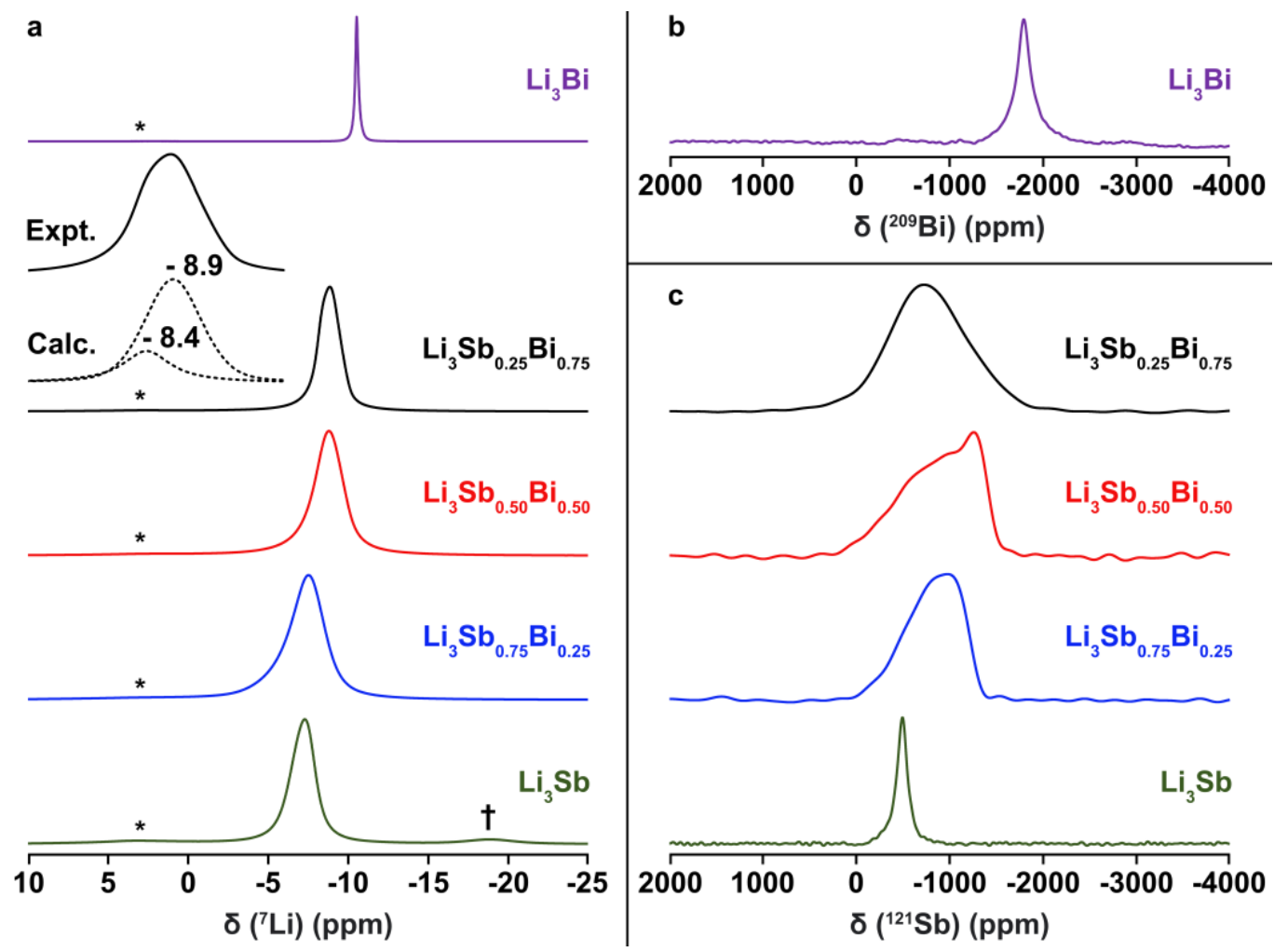

Figure 3. (a) ${ }^{7} \mathrm{Li}$ MAS NMR spectra $\left(\mathrm{B}_{0}=11.75 \mathrm{~T}, \mathrm{~T}=293 \mathrm{~K}, \omega_{\mathrm{r}} / 2 \pi=10 \mathrm{kHz}\right)$ of the $\mathrm{Li}_{3} \mathrm{Sb}_{\mathrm{x}} \mathrm{Bi}_{1-\mathrm{x}}$ alloys. ${ }^{*}$ and $\uparrow$ represent ${ }^{7} \mathrm{Li}$ NMR signals from $\mathrm{Li}_{2} \mathrm{O}$ and $\mathrm{Li}_{2} \mathrm{Sb}$, respectively. (b) Non-spinning ${ }^{209} \mathrm{Bi} \mathrm{NMR}$ spectrum $\left(\mathrm{B}_{0}=11.75 \mathrm{~T}, \mathrm{~T}=293 \mathrm{~K}\right)$ for $\mathrm{Li}_{3} \mathrm{Bi}$. (c) Non-spinning ${ }^{121} \mathrm{Sb}$ NMR spectra $\left(\mathrm{B}_{0}=11.75 \mathrm{~T}, \mathrm{~T}=293 \mathrm{~K}\right)$ of $\mathrm{Li}_{3} \mathrm{Sb}_{\mathrm{x}} \mathrm{Bi}_{1-\mathrm{x}}$ alloys.

Three unique compositional mixtures, $\mathrm{Li}_{3} \mathrm{Sb}_{\mathrm{x}} \mathrm{Bi}_{1-\mathrm{x}}$, where $\mathrm{x}=0.25,0.5$ and 0.75 , reveal ${ }^{7} \mathrm{Li}$ Gaussian-like resonances that are broader $(\mathrm{fwhm}=400-500 \mathrm{~Hz})$ and isotropic chemical shifts located between those for the parent endmembers. These results are consistent with $\mathrm{Sb}$ being incorporated into the lattice across the series and are summarized in Table 2 and Figure 4. Both the unit cell volume and ${ }^{7} \mathrm{Li}$ chemical shift show the largest deviation from a linear trend between $\mathrm{Li}_{3} \mathrm{Bi}$ and $\mathrm{Li}_{3} \mathrm{Sb}$ at $\mathrm{x}_{\mathrm{Sb}}=0.25$. The asymmetric resonance for $\mathrm{Li}_{3} \mathrm{Sb}_{0.25} \mathrm{Bi}_{0.75}$ appears to be composed of two peaks where a minor higher frequency edge is Sb-rich with a similar chemical shift to the $\mathrm{Li}_{3} \mathrm{Sb}_{0.5} \mathrm{Bi}_{0.5}$ composition (Figure 3, inset), that remains post-annealing. $\mathrm{Li}_{3} \mathrm{Sb}_{0.5} \mathrm{Bi}_{0.5}$ and $\mathrm{Li}_{3} \mathrm{Sb}_{0.75} \mathrm{Bi}_{0.25}$ exhibit Gaussian-like lineshapes with minor broadening observed for the $\mathrm{Sb}$ rich phase at the base of the ${ }^{7} \mathrm{Li}$ NMR spectrum which is attributed to a reduction in long-range order (ball milling). This result indicates some local variations in the $\mathrm{Sb} / \mathrm{Bi}$ ratios. Such incipient phase segregation may be due to the differences in Li affinity between $\mathrm{Sb}$ and Bi as reflected by their different plateau voltages in electrochemical experiments, as was discussed earlier. Thermodynamic or DFT calculations assessing the relative stability of a mixture of the binary 
compounds versus a ternary phase could shed further light on this, but none have been published so far. Only $\mathrm{Li}_{3} \mathrm{Sb}_{0.5} \mathrm{Bi}_{0.5}$ has been synthesized before by melting the constituent metals. The lattice parameter was slightly lower than the one we found (6.625 $\AA$ vs. $6.653 \AA)^{45}$, and no traces of $\mathrm{Li}_{3} \mathrm{Bi}$ were reported, indicating that the synthesis route and temperature have a big influence on the outcome.

\section{Table 2. ${ }^{7} \mathrm{Li}$ chemical shifts and activation energies for $\mathrm{Li}$ motion for $\mathrm{Li}_{3} \mathrm{Sb}_{\mathrm{x}} \mathrm{Bi}_{1-\mathrm{x}}$ alloys.}

$\begin{array}{lll}\text { Compound } & { }^{7} \mathrm{Li} \text { chemical shift }(\mathrm{ppm}), \pm 0.1 & \mathrm{E}_{\mathrm{a}}(\mathrm{meV}) \pm 5 \\ \mathrm{Li}_{3} \mathrm{Bi} & -10.5 & 75 \\ \mathrm{Li}_{3} \mathrm{Sb}_{0.25} \mathrm{Bi}_{0.75} & -8.9,-8.4 & 32^{*} \\ \mathrm{Li}_{3} \mathrm{Sb}_{0.5} \mathrm{Bi}_{0.5} & -8.8 & 60^{*} \\ \mathrm{Li}_{3} \mathrm{Sb}_{0.75} \mathrm{Bi}_{0.25} & -7.5 & 75^{*} \\ \mathrm{Li}_{3} \mathrm{Sb} & -7.3 & 53^{*}\end{array}$

*Underestimate of the Ea due to hardware limitations in reaching the high temperature side of the $T_{1}$ curve.

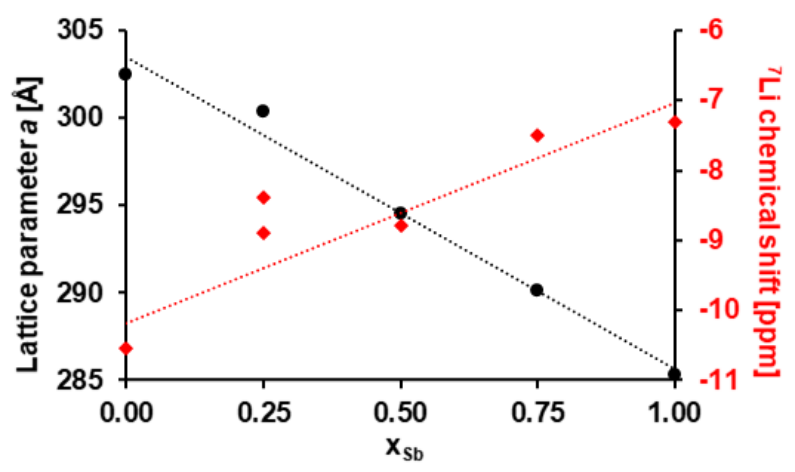

Figure 4. Lattice parameters and ${ }^{7} \mathrm{Li}$ isotropic chemical shifts as a function of $\mathrm{Li}_{3} \mathrm{Sb}_{\mathrm{x}} \mathrm{Bi}_{1-\mathrm{x}}$ alloy composition as determined by ${ }^{7} \mathrm{Li}$ NMR spectroscopy.

Unlike the highly sensitive and relatively narrow lineshapes associated with the ${ }^{7} \mathrm{Li}$ NMR spectra of the A-site, the M-site may contain one or two NMR-active nuclei, namely ${ }^{121 / 123} \mathrm{Sb}$ and ${ }^{209} \mathrm{Bi}$. Although each isotope is found in high natural abundance $\left(57 \%\right.$ for ${ }^{121} \mathrm{Sb}(I=$ $5 / 2), 43 \%$ for ${ }^{123} \mathrm{Sb}(I=7 / 2)$ and $100 \%$ for $\left.{ }^{209} \mathrm{Bi}(I=9 / 2)\right)$, all are half-integer quadrupole nuclear spins, and can suffer from intrinsically broad central transition lineshapes due to their sizeable quadrupole moments. This broadening can further complicate both interpretation and acquisition of their NMR spectra if their electric field gradient (EFG) is non-zero. ${ }^{46-48}$ Fortunately, the parent phases $\left(\mathrm{Li}_{3} \mathrm{M}, \mathrm{M}=\mathrm{Sb}\right.$ or $\left.\mathrm{Bi}\right)$ have local octahedral symmetry within the cubic crystalline phase (i.e., a zero EFG), warranting an attempt to study these sites in more detail. The non-spinning 
${ }^{121} \mathrm{Sb}$ and ${ }^{209} \mathrm{Bi}$ NMR spectra (Figure $3 \mathrm{~b}$, c) show broad Gaussian-like resonances $\left(\mathrm{Li}_{3} \mathrm{Sb}-\mathrm{fwhm}\right.$ $\left.=15 \mathrm{kHz} ; \mathrm{Li}_{3} \mathrm{Bi}-\mathrm{fwhm}=14 \mathrm{kHz}\right)$ with center-of-gravity chemical shifts $\left(\delta_{\mathrm{cgs}}\right)$ of -496 and $-1790 \mathrm{ppm}$, respectively. As predicted based on the crystalline site symmetry, no evidence of second-order quadrupole broadening nor shielding anisotropy is observed for the $\mathrm{M}$ site nuclei of either parent phase. Furthermore, hetero- and homonuclear dipolar coupling does not appear to contribute to the NMR linewidth as virtually no spectral differences were observed between nonspinning and MAS conditions. In contrast to these cubic crystalline systems, the ${ }^{121} \mathrm{Sb}$ NMR of the hexagonal $\mathrm{Li}_{2} \mathrm{Sb}$ phase has two crystallographic inequivalent $\mathrm{Sb}$ sites with similar chemical environments in a pentacapped trigonal prism polyhedron $\left(\mathrm{Li}_{9} \mathrm{Sb}_{2}\right)$. Resolution of two sites is not possible, but fitting the powder pattern reveals a site with an $\delta_{\text {iso }}=-1100 \pm 50 \mathrm{ppm}$, quadrupole coupling constant, $C_{Q}=51.0 \pm 0.7 \mathrm{MHz}$ and an axial symmetry tensor $(\eta=0)$ consistent with the reduction in local symmetry between $\mathrm{Li}_{3} \mathrm{Sb}$ and $\mathrm{Li}_{2} \mathrm{Sb}$ (see Figure $\mathrm{S} 8$ ).

The mixed $\mathrm{Sb} / \mathrm{Bi}$ compounds necessitated the use of the variable offset cumulative spectra (VOCS) acquisition approach to ensure consistent excitation of the broad ${ }^{121} \mathrm{Sb}$ NMR powder patterns that formed upon mixing $\mathrm{Sb}$ and $\mathrm{Bi}$ (i.e., the medium-range order was reduced, resulting in an increase of the electric field gradient about $\mathrm{Sb}$ ). The non-spinning ${ }^{121} \mathrm{Sb} \mathrm{NMR}$ spectra for $\mathrm{Li}_{3} \mathrm{Sb}_{0.75} \mathrm{Bi}_{0.25}$ and $\mathrm{Li}_{3} \mathrm{Sb}_{0.50} \mathrm{Bi}_{0.50}$ clearly indicate multiple $\mathrm{Sb}$ medium-range environments with evidence of second-order quadrupole broadening that is induced by the $\mathrm{Sb} / \mathrm{Bi}$ mixing in the M position, with the broadest resonance ( $\mathrm{fwhm}=\sim 115 \mathrm{kHz}$ ) attributed to the $\mathrm{Li}_{3} \mathrm{Sb}_{0.50} \mathrm{Bi}_{0.50}$ compound, consistent with this composition having random $\mathrm{M}$-site $\mathrm{Sb} / \mathrm{Bi}$ mixing. Unfortunately, due to the sizable second-order quadrupole broadening, and lack of spectral resolution, we cannot deconvolute these data at this time. Acquisition of the ${ }^{209} \mathrm{Bi}$ NMR was unsuccessful for the mixtures even after 72 hours of continuous acquisition. The large chemical shift range, sizable quadrupole broadening, possible short spin-spin $\left(T_{2}\right)$ relaxation or some combination thereof may inhibit detection of a signal at moderate fields. The ${ }^{121} \mathrm{Sb}$ and ${ }^{209} \mathrm{Bi}$ chemical shifts and linewidths as well as those for ${ }^{7} \mathrm{Li}$ under MAS and non-spinning conditions are summarized in Table S1.

\section{Li ion dynamics}

Variable temperature non-spinning ${ }^{7} \mathrm{Li}$ NMR spectroscopy was undertaken to investigate the $\mathrm{Li}$ ion dynamic behavior in these compounds. Figure S9 shows the ${ }^{7} \mathrm{Li}$ NMR spectra obtained between 203 and $333 \mathrm{~K}$. The changes in linewidth, nuclear spin-lattice relaxation and chemical shift are reported in Table S2. At room temperature, the ${ }^{7} \mathrm{Li}$ NMR linewidths are 0.7 to $1.5 \mathrm{kHz}$ across the series, with Bi-rich materials being narrower (faster $\mathrm{Li}$ ion dynamics) than $\mathrm{Sb}$-rich 
sister compounds. All compounds exhibit decreasing linewidths with increasing temperature. Likewise, with increasing temperature (to $333 \mathrm{~K}$ ) the ${ }^{7} \mathrm{Li}$ NMR linewidths decrease as the increased $\mathrm{Li}$ ion motion reduces the residual homonuclear ${ }^{7} \mathrm{Li}-{ }^{7} \mathrm{Li}$ dipolar coupling. The spinlattice relaxation for ${ }^{7} \mathrm{Li}$ is influenced by mobile $\mathrm{Li}$ ions, thus measuring the $T_{1}$ relaxation parameters as a function of temperature allows the associated activation energy for Li dynamics for these materials to be determined using the Arrhenius equation. ${ }^{49-51}$ In the temperature range studied here, all Sb-containing materials display a decrease in their spin-lattice relaxation time with increasing temperature, with all $T_{1}$ values located on the low-temperature side of the $T_{1}$ curve, as shown in Figure S10. Using these data, the Sb-containing materials were found to range from 32 to $75 \mathrm{meV}$, as shown in Table 2. In contrast to the Sb-containing phases, the $T_{1}$ minimum for $\mathrm{Li}_{3} \mathrm{Bi}$ is found at $233 \mathrm{~K}$, revealing that $\mathrm{Li}$ ions are moving rapidly within this phase where the correlation time for $\mathrm{Li}\left(T_{1}\right.$ minimum) can be obtained and an activation energy of $75 \pm 5 \mathrm{meV}$ is determined from the more accurate high-temperature side of the $T_{1}$ curve. The interplay between the fast and slow-motion limits reveals that at $233 \mathrm{~K}, \mathrm{Li}$ ion diffusion is occurring at approximately the ${ }^{7} \mathrm{Li}$ nuclear Larmor frequency (ns timescale, $\sim 0.8 \mathrm{~ns}$ ), increasing at higher temperatures approaching the value reported for fast solid ionic conductors, consistent with the narrow Lorentzian lineshape observed above. The associated $\mathrm{Li}_{3} \mathrm{Bi}$ activation energy agrees well with prior conductance measurements $\left(E_{a}<100 \mathrm{meV}\right)$, whereas the NMR results appear to underestimate $\mathrm{Li}_{3} \mathrm{Sb}$ and associated mixtures which is attributed to the inability to reach high temperature side of the $T_{1}$ curve (due to hardware limitations) resulting in an underestimation of activation energy. ${ }^{52}$ The discrepancy for $\mathrm{Li}_{3} \mathrm{Bi}$ may be attributed to how the techniques respond to Li ion diffusion: NMR spectroscopy is sensitive to medium- and short-range structure, while conductivity measurement methods respond to bulk solid properties, probing long-range macroscopic dynamics whereby grain boundaries, defects or compositional/structural variations, for example that can influence the measurements. For example, an early NMR study provided evidence of lithium ion dynamics within $\mathrm{Li}_{3} \mathrm{Sb},{ }^{53}$ while lithium diffusion and conductivities were reported on bulk $\mathrm{Li}_{3} \mathrm{Sb}$ and $\mathrm{Li}_{3} \mathrm{Bi}$ materials using the galvanostatic intermittent titration technique (GITT). ${ }^{52,54}$ Using GITT, the authors demonstrated that variations in activation energy (200-300 $\mathrm{meV}$ for $\mathrm{Li}_{3} \mathrm{Sb}$, and $\leq 130 \mathrm{meV}$ for $\mathrm{Li}_{3} \mathrm{Bi}$ ) were due to small deviations from the 3:1 stoichiometric ratio for the materials that impacted the measured activation energy. ${ }^{54}$ Therefore, the new synthetic approach (mechanochemical synthesis) used to provide single-phase crystalline materials that exhibit varying degrees of local order, may contribute to the variations in activation energies. Recently, this phenomenon has also been observed in other ionic conducting 
materials. ${ }^{55-58}$ We also caution that values determined from the GITT method date back nearly four decades and it has since been suggested that the approach may provide spurious results. ${ }^{59}$

\section{CONCLUSIONS}

The long, and short range order of the $\mathrm{Li}_{3}\left(\mathrm{Sb}_{\mathrm{x}} \mathrm{Bi}_{1-\mathrm{x}}\right)$ alloys were studied using $\mathrm{X}$-ray diffraction and NMR spectroscopy, respectively. For $\mathrm{x}=0.25$, the fcc unit cell volume determined by XRD showed a positive deviation from Vegard's law, indicative of a tendency towards phase segregation even though only a single crystalline phase could be determined. For $\mathrm{x}=0.50$, the asmilled material consisted of two fcc phases and subsequent annealing treatment decreased the relative quantity of the Bi-enriched phase as observed by XRD. NMR spectroscopy supported formation of Sb-rich clusters in these ternary alloys. The low activation energies determined by nuclear spin lattice relaxation measurements suggest that these alloys would have a high rate capability when used as a Li-ion battery anode, in particular $\mathrm{Li}_{3} \mathrm{Bi}$. When a 2:1 Li:Sb mixture was milled, $\mathrm{Li}_{3} \mathrm{Sb}$ and $\mathrm{Sb}$ metal were observed to form instead of the $\mathrm{Li}_{2} \mathrm{Sb}$ compound. This result shows that direct contact between $\mathrm{Sb}_{\mathrm{x}} \mathrm{Bi}_{1-\mathrm{x}}$ and $\mathrm{Li}$ metal during milling is equivalent to setting an electrochemical half-cell to $0 \mathrm{~V}$, thus leading to immediate formation of the phase with the highest Li content. This reaction mechanism is quite different from what would be expected under the operating conditions in a battery. Therefore, in-situ diffraction experiments on these binary $\mathrm{Sb}_{\mathrm{x}} \mathrm{Bi}_{1-\mathrm{x}}$ solid solutions, both under constant current and constant potential conditions, would be an interesting direction for future research.

\section{ASSOCIATED CONTENT}

\section{Supporting Information}

Photo of air-tight PP-covered Kapton windows used for XRD, additional diffraction patterns related to $\mathrm{Sb}-\mathrm{Bi}$ and Li-Sb-Bi alloy synthesis. ${ }^{121} \mathrm{Sb}$ NMR spectrum of $\mathrm{Li}_{2} \mathrm{Sb}$ compound and static variable temperature ${ }^{7} \mathrm{Li}$ NMR spectra of all compounds. Tables with chemical shifts and line widths for MAS and static ${ }^{7} \mathrm{Li},{ }^{121} \mathrm{Sb}$ and ${ }^{208} \mathrm{Bi}$ NMR spectra at room temperature and ${ }^{7} \mathrm{Li}$ at variable temperature. 


\section{AUTHOR INFORMATION}

\section{Corresponding Authors}

*E-mail: pkalisva@ualberta.ca

*E-mail: vmichael@ualberta.ca

*E-mail: jburiak@ualberta.ca

\section{ORCID}

Authors Jillian Buriak: 0000-0002-9567-4328

Vladimir K Michaelis: 0000-0002-6708-7660

W. Peter Kalisvaart: 0000-0003-1228-906X

Amit Bhattacharya: 0000-0002-3104-9187

Madhusudan Chaudhary: 0000-0002-5076-7942

\section{Notes}

The authors declare no competing financial interest.

\section{ACKNOWLEDGMENTS}

This work was supported by Western Economic Diversification (WD, grant number 14328), NSERC Discovery grants (RGPIN-2018-04294 and RGPIN-2021-02540) and CREATE programs (Alberta-Technical University of Munich International Graduate School, ATUMS), the Canada Research Chairs program (CRC 207142 and CRC 2020-00352). The University of Alberta Centre for Nanofabrication (the nanoFAB) and the National Research Council-Edmonton are thanked for the use of facilities. The Canada Foundation for Innovation and Government of Alberta are acknowledged for supporting NMR and materials characterization infrastructure at the Universit of Alberta.

\section{REFERENCES}

(1) Schulze, M. C.; Belson, R. M.; Kraynak, L. A.; Prieto, A. L. Electrodeposition of $\mathrm{Sb} / \mathrm{CNT}$ Composite Films as Anodes for Li- and Na-Ion Batteries. Energy Storage Materials 2020, 25, 572-584.

(2) Guo, S.; Li, H.; Lu, Y.; Liu, Z.; Hu, X. Lattice Softening Enables Highly Reversible Sodium Storage in Anti-Pulverization Bi-Sb Alloy/Carbon Nanofibers. Energy Storage Mater. 2020, 27, 270-278. 
(3) Wang, S.; Yang, X.; Lee, P.-K.; Rogach, A. L.; Yu, D. Y. W. Reversible Interaction of $\mathrm{Sb}$ with an Active Se Matrix Enhances the Cycle Stability of Electrodes for Lithium-Ion Batteries. Chem. Mater. 2019, 31, 2469-2475.

(4) Wang, C.; Chen, G.; Kou, J.; Zhang, X.; Xu, X.; Bao, J.; Shen, Z.; Jin, X.; Zhang, H.; Liu, L.; et al. Sb@S-N-C Nanocomposite as Long-Cycle Stable Anode Material for Lithium Ion Batteries. J. Alloys Compd. 2020, 814, 152161.

(5) Yi, Z.; Han, Q.; Zan, P.; Wu, Y.; Cheng, Y.; Wang, L. Sb Nanoparticles Encapsulated into Porous Carbon Matrixes for High-Performance Lithium-Ion Battery Anodes. J. Power Sources 2016, 331, 16-21.

(6) Xie, H.; Peter Kalisvaart, W.; C. Olsen, B.; J. Luber, E.; Mitlin, D.; M. Buriak, J. Sn-BiSb Alloys as Anode Materials for Sodium Ion Batteries. J. Mater. Chem. A 2017, 5, 9661-9670.

(7) Xie, H.; Tan, X.; Luber, E. J.; Olsen, B. C.; Kalisvaart, W. P.; Jungjohann, K. L.; Mitlin, D.; Buriak, J. M. B-SnSb for Sodium Ion Battery Anodes: Phase Transformations Responsible for Enhanced Cycling Stability Revealed by In Situ TEM. ACS Energy Lett. 2018, 3, 1670-1676.

(8) Zhao, Y.; Manthiram, A. High-Capacity, High-Rate Bi-Sb Alloy Anodes for Lithium-Ion and Sodium-Ion Batteries. Chem. Mater. 2015, 27, 3096-3101.

(9) Kalisvaart, W. P.; Olsen, B. C.; Luber, E. J.; Buriak, J. M. Sb-Si Alloys and Multilayers for Sodium Ion Battery Anodes. ACS Appl. Mater. Interfaces 2019, 2, 2205-2213.

(10) Kalisvaart, W. P.; Xie, H.; Olsen, B. C.; Luber, E. J.; Buriak, J. M. Understanding the Mechanism of Enhanced Cycling Stability in Sn-Sb Composite Na-Ion Battery Anodes: Operando Alloying and Diffusion Barriers. ACS Appl. Energy Mater. 2019, 2, 5133-5139.

(11) Kubota, K.; Shimadzu, S.; Yabuuchi, N.; Tominaka, S.; Shiraishi, S.; Abreu-Sepulveda, M.; Manivannan, A.; Gotoh, K.; Fukunishi, M.; Dahbi, M.; et al. Structural Analysis of SucroseDerived Hard Carbon and Correlation with the Electrochemical Properties for Lithium, Sodium, and Potassium Insertion. Chem. Mater. 2020, 32, 2961-2977.

(12) Peters, J. F.; Abdelbaky, M.; Baumann, M.; Weil, M. A Review of Hard Carbon Anode Materials for Sodium-Ion Batteries and Their Environmental Assessment. Matériaux \& Techniques 2019, 107, 503. 
(13) Lotfabad, E. M.; Ding, J.; Cui, K.; Kohandehghan, A.; Kalisvaart, W. P.; Hazelton, M.; Mitlin, D. High-Density Sodium and Lithium Ion Battery Anodes from Banana Peels. ACS Nano 2014, 8, 7115-7129.

(14) Yang, X.; Zhang, R.; Xu, S.; Xu, D.; Ma, J.; Zhang, Z.; Yang, S. Graphene/ Amorphous Carbon Restriction Structure for Stable and Long-lifespan Antimony Anode in K-ion Batteries. Chem. Eur. J. 2020, chem.201905311.

(15) Gabaudan, V.; Berthelot, R.; Stievano, L.; Monconduit, L. Inside the Alloy Mechanism of Sb and Bi Electrodes for K-Ion Batteries. J. Phys. Chem. C 2018, 122, 18266-18273.

(16) Okamoto, H. Desk Handbook: Phase Diagrams for Binary Alloys; ASM International, 2000.

(17) Alloy Phase Diagram Database https://matdata.asminternational.org/apd/index.aspx (accessed Feb 12, 2019).

(18) Westman, K.; Dugas, R.; Jankowski, P.; Wieczorek, W.; Gachot, G.; Morcrette, M.; Irisarri, E.; Ponrouch, A.; Palacín, M. R.; Tarascon, J.-M.; et al. Diglyme Based Electrolytes for Sodium-Ion Batteries. ACS Appl. Energy Mater. 2018, 1, 2671-2680.

(19) Zhang, B.; Rousse, G.; Foix, D.; Dugas, R.; Corte, D. A. D.; Tarascon, J.-M. Microsized Sn as Advanced Anodes in Glyme-Based Electrolyte for Na-Ion Batteries. Adv. Mater. 2016, 28, 9824-9830.

(20) Kim, C.; Kim, I.; Kim, H.; Sadan, M. K.; Yeo, H.; Cho, G.; Ahn, J.; Ahn, J.; Ahn, H. A Self-Healing Sn Anode with an Ultra-Long Cycle Life for Sodium-Ion Batteries. J. Mater. Chem. A 2018, 6, 22809-22818.

(21) Manasijević, D.; Vřeštál, J.; Minić, D.; Kroupa, A.; Živković, D.; Živković, Ž. Phase Equilibria and Thermodynamics of the Bi-Sb-Sn Ternary System. J. Alloys Compds. 2007, 438, $150-157$.

(22) Darwiche, A.; Marino, C.; Sougrati, M. T.; Fraisse, B.; Stievano, L.; Monconduit, L. Better Cycling Performances of Bulk Sb in Na-Ion Batteries Compared to Li-Ion Systems: An Unexpected Electrochemical Mechanism. J. Am. Chem. Soc. 2012, 134, 20805-20811. 
(23) Ellis, L. D.; Wilkes, B. N.; Hatchard, T. D.; Obrovac, M. N. In Situ XRD Study of Silicon, Lead and Bismuth Negative Electrodes in Nonaqueous Sodium Cells. J. Electrochem. Soc. 2014, 161, A416-A421.

(24) Hewitt, K. C.; Beaulieu, L. Y.; Dahn, J. R. Electrochemistry of InSb as a Li Insertion Host: Problems and Prospects. J. Electrochem. Soc. 2001, 148, A402.

(25) Goonetilleke, D.; Sharma, N.; Kimpton, J.; Galipaud, J.; Pecquenard, B.; Le Cras, F. Insight into the Formation of Lithium Alloys in All-Solid-State Thin Film Lithium Batteries. Front. Energy Res. 2018, 6.

(26) Karmakar, A.; Mukhopadhyay, S.; Gachod, P. G. B.; Mora-Gomez, V. A.; Bernard, G. M.; Brown, A.; Michaelis, V. K. Uncovering Halogen Mixing and Octahedral Dynamics in $\mathrm{Cs}_{2} \mathrm{SnX}_{6}$ by Multinuclear Magnetic Resonance Spectroscopy. Chem. Mater. 2021, 33, 60786090 .

(27) Liu, X.; Liang, Z.; Xiang, Y.; Lin, M.; Li, Q.; Liu, Z.; Zhong, G.; Fu, R.; Yang, Y. SolidState NMR and MRI Spectroscopy for Li/Na Batteries: Materials, Interface, and In Situ Characterization. Adv. Mater. 2021, 2005878.

(28) Manivasagam, T. G.; Magusin, P. C. M. M.; Iliksu, M.; Notten, P. H. L. Influence of Nickel and Silicon Addition on the Deuterium Siting and Mobility in fcc Mg-Ti Hydride Studied with 2H MAS NMR. J. Phys. Chem. C 2014, 118, 10606-10615.

(29) Kalisvaart, W. P.; Latroche, M.; Cuevas, F.; Notten, P. H. L. In Situ Neutron Diffraction Study on Pd-Doped $\mathrm{Mg}_{0.65} \mathrm{Sc}_{0.35}$ Electrode Material. J. Solid State Chem. 2008, 181, 1141-1148.

(30) Latroche, M.; Kalisvaart, P.; Notten, P. H. L. Crystal Structure of $\mathrm{Mg}_{0.65} \mathrm{Sc}_{0.35} \mathrm{Dx}$ Deuterides Studied by X-Ray and Neutron Powder Diffraction. J. Solid State Chem. 2006, 179, 3024-3032.

(31) Magusin, P. C. M. M.; Kalisvaart, W. P.; Notten, P. H. L.; van Santen, R. A. Hydrogen Sites and Dynamics in Light-Weight Hydrogen-Storage Material Magnesium-Scandium Hydride Investigated with ${ }^{1} \mathrm{H}$ and ${ }^{2} \mathrm{H}$ NMR. Chem. Phys. Lett. 2008, 456, 55-58.

(32) Grey, C. P.; Dupré, N. NMR Studies of Cathode Materials for Lithium-Ion Rechargeable Batteries. Chem. Rev. 2004, 104, 4493-4512. 

in Battery Research. Chem. Mater. 2017, 29, 213-242.

(34) Li, X.; Tang, M.; Feng, X.; Hung, I.; Rose, A.; Chien, P.-H.; Gan, Z.; Hu, Y.-Y. Lithiation and Delithiation Dynamics of Different Li Sites in Li-Rich Battery Cathodes Studied by Operando Nuclear Magnetic Resonance. Chem. Mater. 2017, 29, 8282-8291.

(35) Cahill, L. S.; Chapman, R. P.; Kirby, C. W.; Goward, G. R. The Challenge of Paramagnetism in Two-Dimensional ${ }^{6,7}$ Li Exchange NMR. Appl Magn Reson 2007, 32, 565-581.

(36) Michaelis, V. K.; Levin, K.; Germanov, Y.; Lelong, G.; Kroeker, S. Ultrahigh-Resolution ${ }^{7}$ Li Magic-Angle Spinning Nuclear Magnetic Resonance Spectroscopy by Isotopic Dilution. Chem. Mater. 2018, 30, 5521-5526.

(37) Freytag, A. I.; Pauric, A. D.; Krachkovskiy, S. A.; Goward, G. R. In Situ Magic-Angle Spinning ${ }^{7}$ Li NMR Analysis of a Full Electrochemical Lithium-Ion Battery Using a Jelly Roll Cell Design. J. Am. Chem. Soc. 2019, 141, 13758-13761.

(38) Freytag, A. I.; Pauric, A. D.; Jiang, M.; Goward, G. R. ${ }^{7}$ Li and ${ }^{29}$ Si NMR Enabled by High-Density Cellulose-Based Electrodes in the Lithiation Process in Silicon and Silicon Monoxide Anodes. J. Phys. Chem. C 2019, 123, 11362-11368.

(39) Chang, D.; Huo, H.; E. Johnston, K.; Ménétrier, M.; Monconduit, L.; P. Grey, C.; Ven, A. V. der. Elucidating the Origins of Phase Transformation Hysteresis During Electrochemical Cycling of Li-Sb Electrodes. J. Mater. Chem. A 2015, 3, 18928-18943.

(40) Champagne, P.-L.; Ester, D.; Bhattacharya, A.; Hofstetter, K.; Zellman, C.; Bag, S.; Yu, H.; Trudel, S.; Michaelis, V. K.; Williams, V. E.; et al. Liquid Crystalline Lithium-Ion Electrolytes Derived from Biodegradable Cyclodextrin. J. Mater. Chem. A 2019, 7, 1220112213.

(41) Conradi, M. S.; Mendenhall, M. P.; Ivancic, T. M.; Carl, E. A.; Browning, C. D.; Notten, P. H. L.; Kalisvaart, W. P.; Magusin, P. C. M. M.; Bowman, R. C.; Hwang, S.-J.; et al. NMR to Determine Rates of Motion and Structures in Metal-Hydrides. J. Alloys Compds. 2007, 446-447, 499-503.

(42) Allan, P. K.; Griffin, J. M.; Darwiche, A.; Borkiewicz, O. J.; Wiaderek, K. M.; Chapman, K. W.; Morris, A. J.; Chupas, P. J.; Monconduit, L.; Grey, C. P. Tracking Sodium-Antimonide 
Phase Transformations in Sodium-Ion Anodes: Insights from Operando Pair Distribution Function Analysis and Solid-State NMR Spectroscopy. J. Am. Chem. Soc. 2016, 138, 2352-2365.

(43) Massiot, D.; Farnan, I.; Gautier, N.; Trumeau, D.; Trokiner, A.; Coutures, J. P. ${ }^{71}$ Ga and ${ }^{69} \mathrm{Ga}$ Nuclear Magnetic Resonance Study of $\beta-\mathrm{Ga}_{2} \mathrm{O}_{3}$ : Resolution of Four- and Six-Fold Coordinated Ga Sites in Static Conditions. Solid State Nucl. Magn. Reson. 1995, 4, 241-248.

(44) Pavlyuk, V.; Sozanskyi, M.; Dmytriv, G.; Indris, S.; Ehrenberg, H. Amendment of the LiBi Phase Diagram Crystal and Electronic Structure of Li2Bi. J. Phase Equilib. Diffus. 2015, 36, $544-553$.

(45) Leonova, M. E.; Sevast'yanova, L. G.; Gulish, O. K.; Burdina, K. P. New Cubic Phases in the Li-Na-Sb-Bi System. Inorg. Mater. 2001, 37, 1270-1273.

(46) Hamaed, H.; Laschuk, M. W.; Terskikh, V. V.; Schurko, R. W. Application of SolidState ${ }^{209} \mathrm{Bi}$ NMR to the Structural Characterization of Bismuth-Containing Materials. J. Am. Chem. Soc. 2009, 131, 8271-8279.

(47) Faucher, A.; Terskikh, V. V.; Wasylishen, R. E. Feasibility of Arsenic and Antimony NMR Spectroscopy in Solids: An Investigation of Some Group 15 Compounds. Solid State Nucl. Magn. Reson. 2014, 61-62, 54-61.

(48) Karmakar, A.; Bernard, G. M.; Meldrum, A.; Oliynyk, A. O.; Michaelis, V. K. Tailorable Indirect to Direct Band-Gap Double Perovskites with Bright White-Light Emission: Decoding Chemical Structure Using Solid-State NMR. J. Am. Chem. Soc. 2020, 142, 10780-10793.

(49) Wilkening, M.; Heitjans, P. From Micro to Macro: Access to Long-Range Li+ Diffusion Parameters in Solids via Microscopic ${ }^{6,7}$ Li Spin-Alignment Echo NMR Spectroscopy. ChemPhysChem 2012, 13, 53-65.

(50) Xiang, Y.-X.; Zheng, G.; Zhong, G.; Wang, D.; Fu, R.; Yang, Y. Toward Understanding of Ion Dynamics in Highly Conductive Lithium Ion Conductors: Some Perspectives by Solid State NMR Techniques. Solid State Ionics 2018, 318, 19-26.

(51) Bloembergen, N.; Purcell, E. M.; Pound, R. V. Relaxation Effects in Nuclear Magnetic Resonance Absorption. Phys. Rev. 1948, 73, 679-712. 
(52) Weppner, W.; Huggins, R. A. Determination of the Kinetic Parameters of MixedConducting Electrodes and Application to the System $\mathrm{Li}_{3} \mathrm{Sb}$. J. Electrochem. Soc. 1977, 124, 1569.

(53) Ossman, G. W.; McGrath, J. W. Nuclear Magnetic Resonance Study of $\mathrm{Li}_{3} \mathrm{Sb}, \mathrm{Na}_{3} \mathrm{Sb}$, and $\mathrm{Na}_{3} \mathrm{As}$ Powders. J. Chem. Phys. 1968, 49, 783-788.

(54) Electrochemical Investigation of the Chemical Diffusion, Partial Ionic Conductivities, and Other Kinetic Parameters in $\mathrm{Li}_{3} \mathrm{Sb}$ and $\mathrm{Li}_{3} \mathrm{Bi}$. J. Solid State Chem. 1977, 22, 297-308.

(55) Stamminger, A. R.; Ziebarth, B.; Mrovec, M.; Hammerschmidt, T.; Drautz, R. Ionic Conductivity and Its Dependence on Structural Disorder in Halogenated Argyrodites $\mathrm{Li}_{6} \mathrm{PS}_{5} \mathrm{X}(\mathrm{X}$ $=\mathrm{Br}, \mathrm{Cl}, \mathrm{I})$. Chem. Mater. 2019, 31, 8673-8678.

(56) Hanghofer, I.; Brinek, M.; Eisbacher, S. L.; Bitschnau, B.; Volck, M.; Hennige, V.; Hanzu, I.; Rettenwander, D.; Wilkening, H. M. R. Substitutional Disorder: Structure and Ion Dynamics of the Argyrodites $\mathrm{Li}_{6} \mathrm{PS}_{5} \mathrm{Cl}, \mathrm{Li}_{6} \mathrm{PS}_{5} \mathrm{Br}$ and $\mathrm{Li}_{6} \mathrm{PS}_{5} \mathrm{I}$. Phys. Chem. Chem. Phys. 2019 , $21,8489-8507$.

(57) Xiong, S.; Liu, Z.; Rong, H.; Wang, H.; McDaniel, M.; Chen, H. Na $\mathrm{SbSe}_{4-\mathrm{x}} \mathrm{S}_{\mathrm{x}}$ as Sodium Superionic Conductors. Sci. Rep. 2018, 8, 9146.

(58) Adeli, P.; Bazak, J. D.; Park, K. H.; Kochetkov, I.; Huq, A.; Goward, G. R.; Nazar, L. F. Boosting Solid-State Diffusivity and Conductivity in Lithium Superionic Argyrodites by Halide Substitution. Angew. Chem. Int. Ed. 2019, 58, 8681-8686.

(59) Deiss, E. Spurious Chemical Diffusion Coefficients of $\mathrm{Li}^{+}$in Electrode Materials Evaluated with GITT. Electrochim. Acta 2005, 50, 2927-2932. 
Table of Contents image

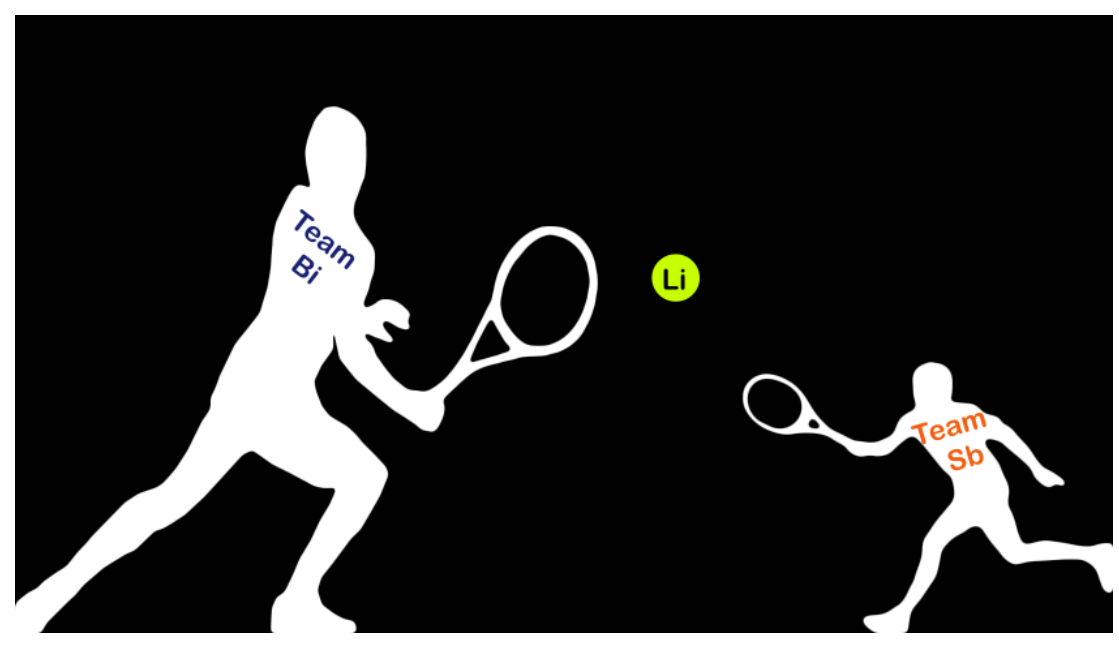




\section{Supporting Information}

\section{Mixing, Domains, and Fast Li-ion Dynamics in Ternary Li-Sb-Bi Battery Anode Alloys}

W. Peter Kalisvaart, ${ }^{*}$ Madhusudan Chaudhary, Amit Bhattacharya, Vladimir K. Michaelis*, Jillian M. Buriak*

Department of Chemistry, University of Alberta, 11227 Saskatchewan Drive, Edmonton, AB T6G 2G2, Canada

*Corresponding authors. Email addresses:

pkalisva@ualberta.ca (W. Peter Kalisvaart),

vmichael@ualberta.ca (Vladimir K. Michaelis),

jburiak@ualberta.ca (Jillian M. Buriak) 


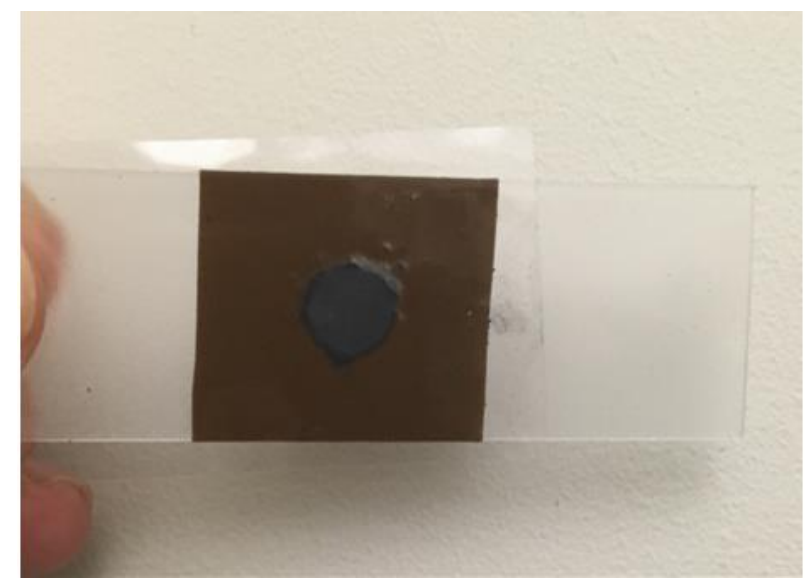

Figure S1. Glass slide with the PP-covered Kapton cutout containing Li alloy powder for XRD.

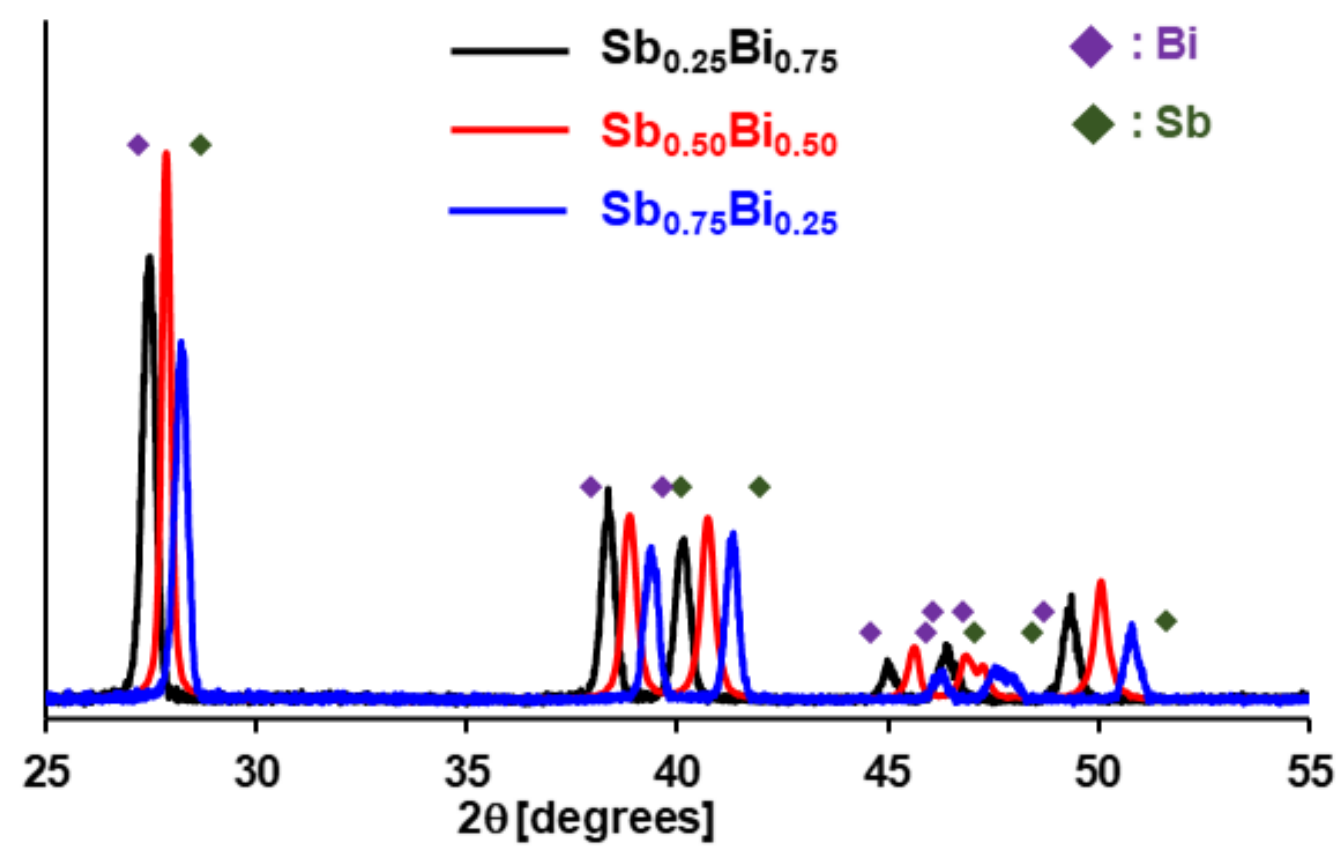

Figure S2. XRD patterns of $\mathrm{Sb}_{\mathrm{x}} \mathrm{Bi}_{1-\mathrm{x}}$ metal powders for $\mathrm{x}=0.25,0.50$ and 0.75 after milling and annealing. The theoretical peak positions of $\mathrm{Bi}$ and $\mathrm{Sb}$ metals are marked by the purple and dark green diamonds and illustrate the continuous shift of the peaks with composition. 


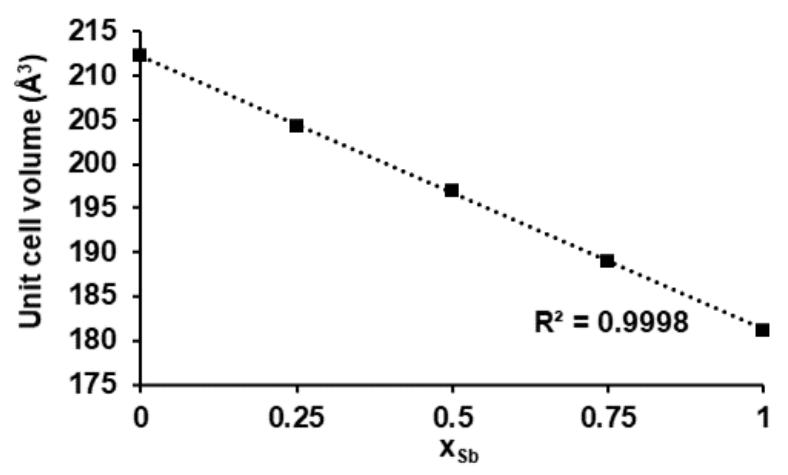

Figure S3. Correlation between unit cell volume and composition for $\mathrm{Sb}_{\mathrm{x}} \mathrm{Bi}_{1-\mathrm{x}}$ alloys.
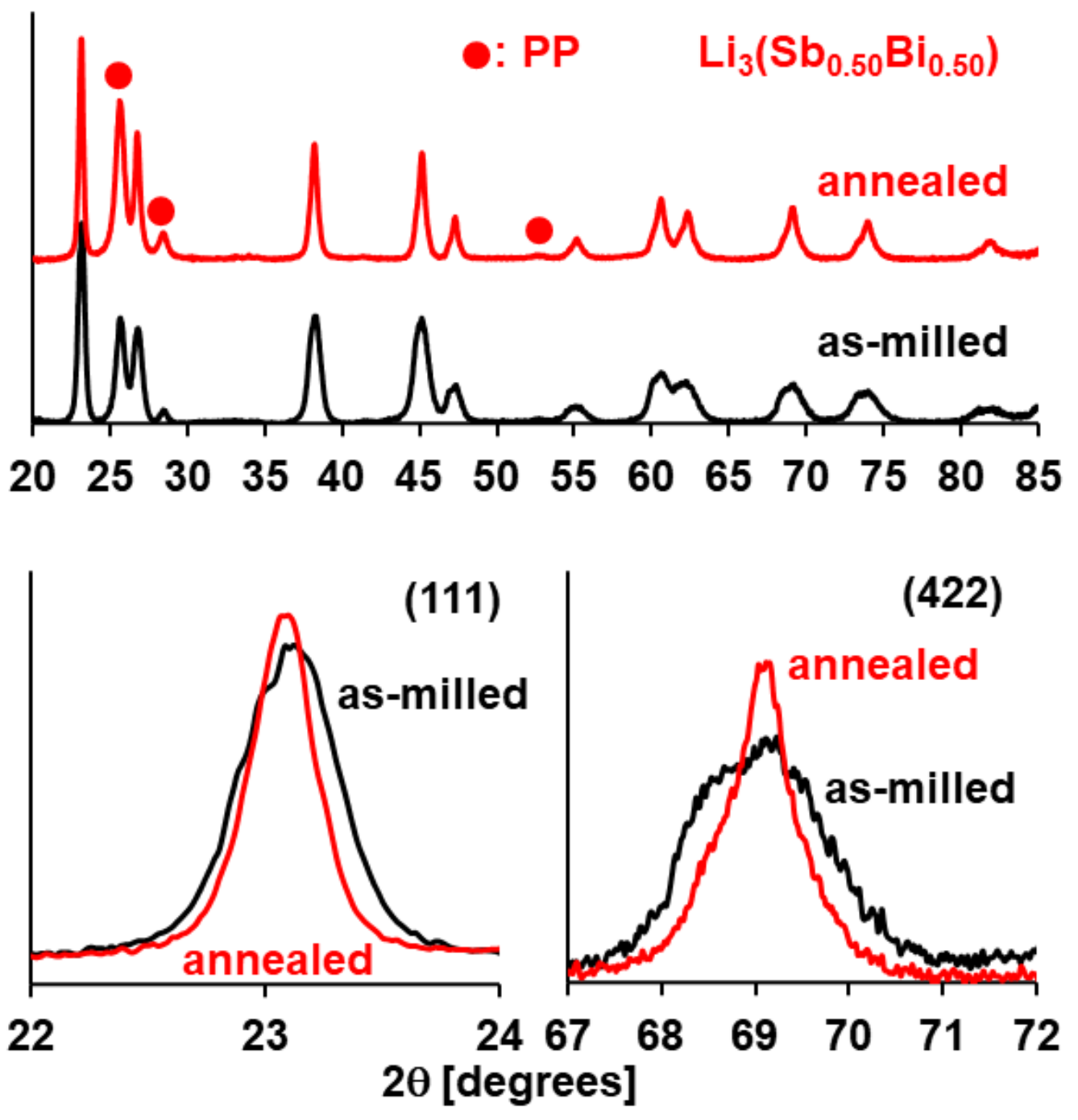

Figure S4. XRD patterns of as-milled (black) and annealed (red) $\mathrm{Li}_{3} \mathrm{Sb}_{0.50} \mathrm{Bi}_{0.50}$ alloy powder. The solid dots mark the positions of the strongest peaks due to the PP foil. All other peaks belong to the $\mathrm{Li}_{3} \mathrm{Sb}_{0.50} \mathrm{Bi}_{0.50} \mathrm{fcc}$ phase(s). Narrowing of the peaks after annealing as well as decreasing intensity of secondary phases is highlighted in the bottom panels depicting the (111) and (422) peaks. 


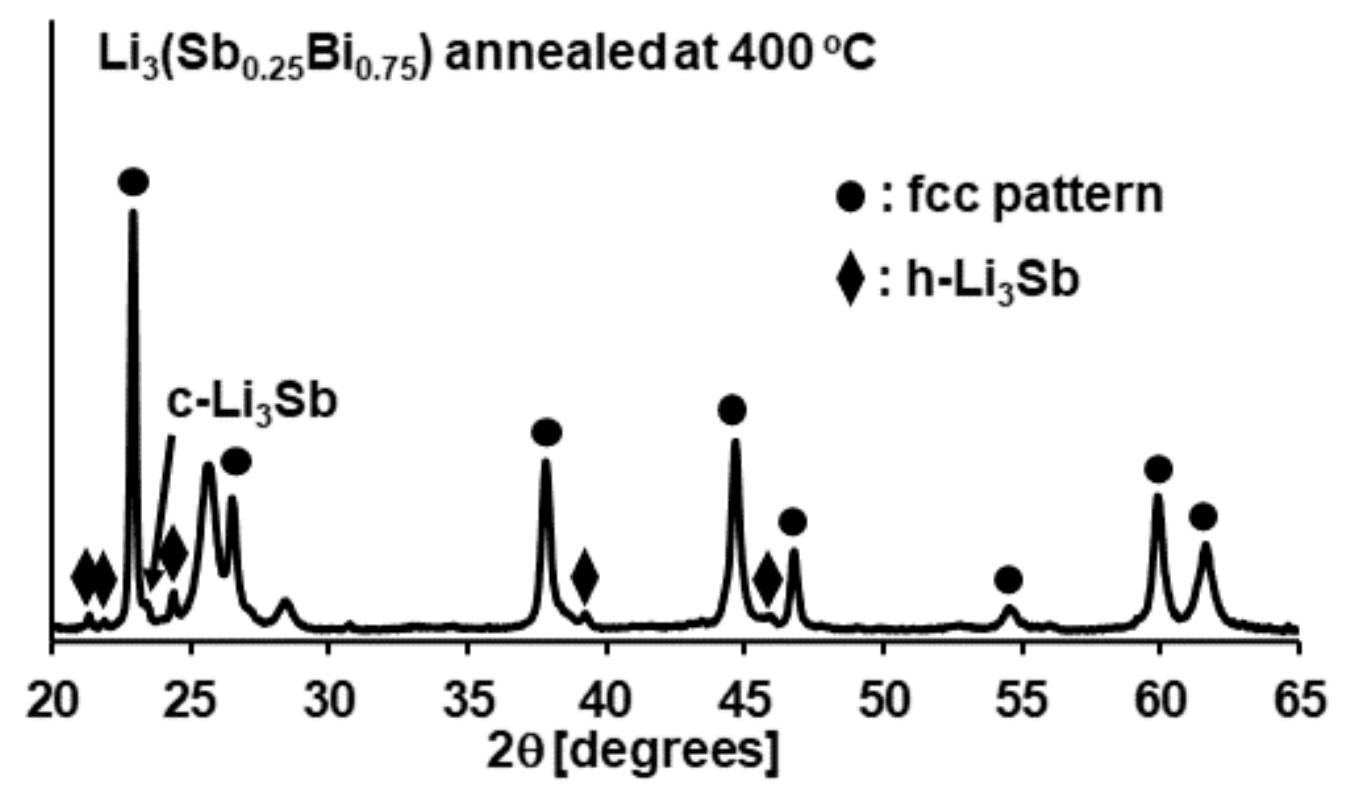

Figure S5. XRD pattern of $\mathrm{Li}_{3}\left(\mathrm{Sb}_{0.25} \mathrm{Bi}_{0.75}\right)$ synthesized at $400{ }^{\circ} \mathrm{C}$ in the same manner as $\mathrm{Li}_{3} \mathrm{Bi}$; by wrapping a metal pellet in $\mathrm{Li}$ foil. Note the presence of high-temperature hexagonal $\mathrm{Li}_{3} \mathrm{Sb}$, indicated by the kite markers. Despite the high Bi content, ball-milling synthesis at room-temperature is possible for this material, as shown in the front matter.

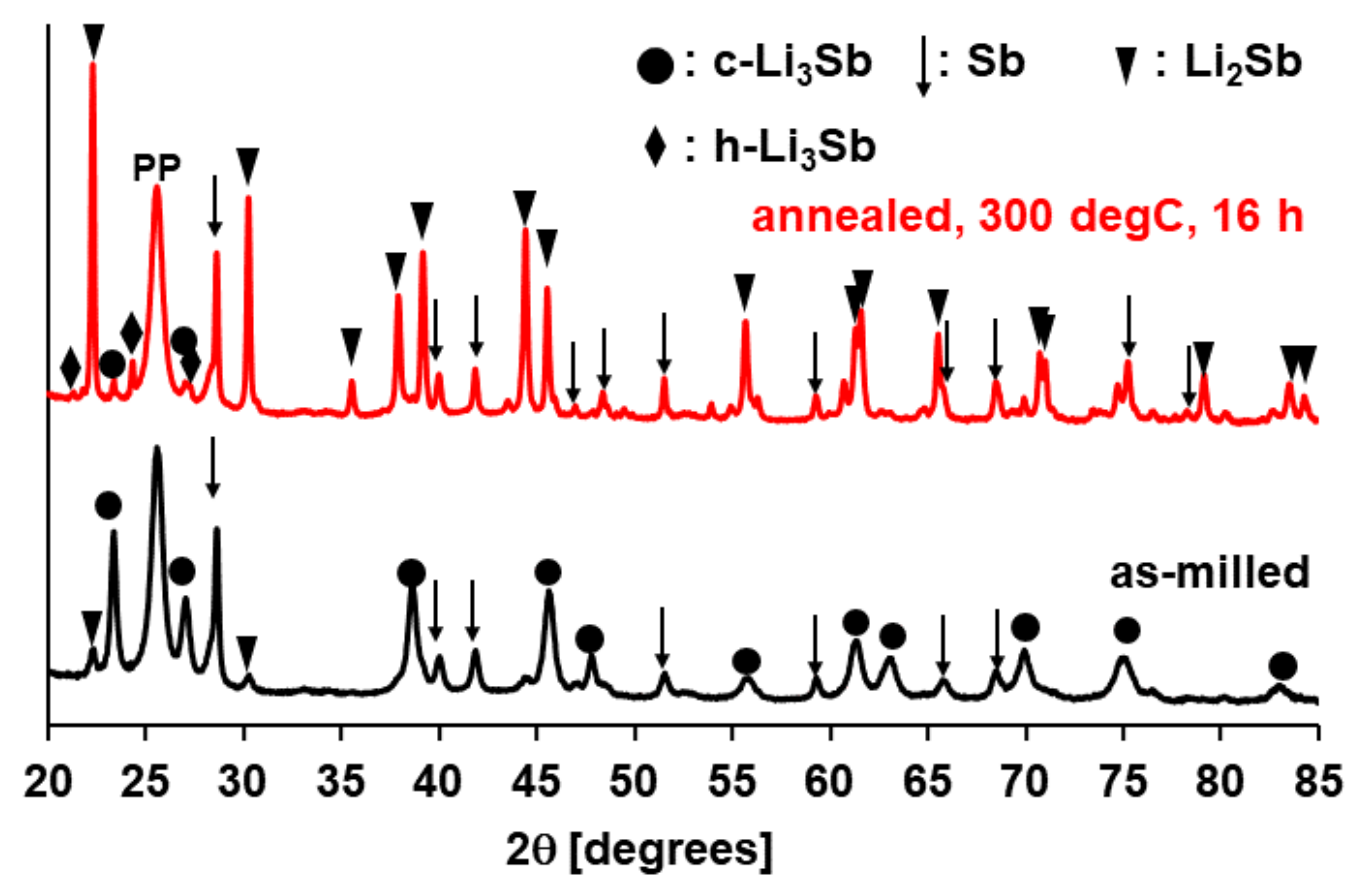

Figure S6. XRD patterns of as-milled and annealed $\mathrm{Li}_{2} \mathrm{Sb}$ powder. Note the transformation, due to the annealing step, from having $\mathrm{Li}_{3} \mathrm{Sb}$ as the major phase to $\mathrm{Li}_{2} \mathrm{Sb}$ being most abundant. Traces of $\mathrm{Sb}$ metal and cubic $\mathrm{Li}_{3} \mathrm{Sb}$ are still present as well as a minor trace of high-temperature (hexagonal) $\mathrm{Li}_{3} \mathrm{Sb}$. The formation of $\mathrm{h}-\mathrm{Li}_{3} \mathrm{Sb}$ is unexpected, since the transformation temperature of $\mathrm{c}-\mathrm{Li}_{3} \mathrm{Sb}$ is given at $460-650{ }^{\circ} \mathrm{C}^{1}$. The presence of $\mathrm{Li}_{2} \mathrm{Sb}$ may possibly lower the activation barrier for $\mathrm{h}-\mathrm{Li}_{3} \mathrm{Sb}$ formation. 


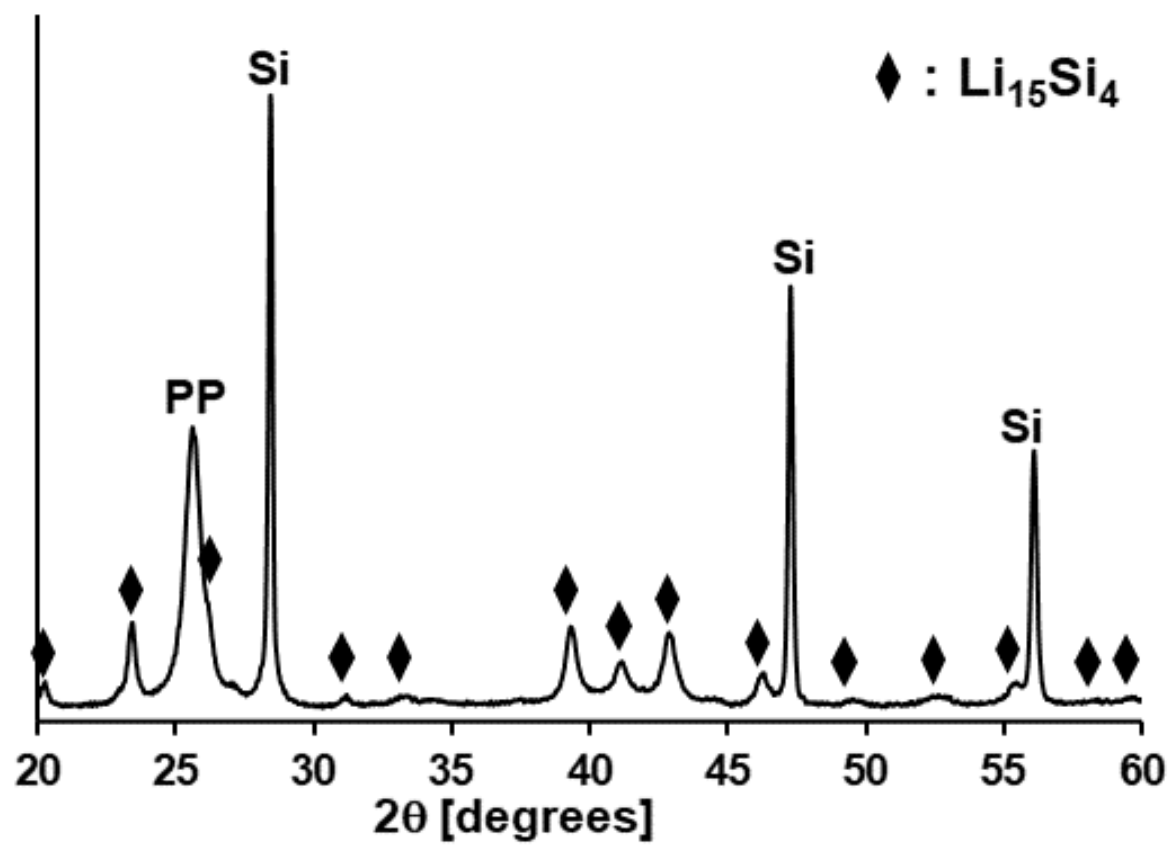

Figure S7. XRD pattern of as-milled $\mathrm{Li}_{9} \mathrm{Si}_{4}$. Despite the overall composition being close to $\mathrm{Li}_{7} \mathrm{Si}_{3}$ stoichiometry, which is a stable intermetallic according to the equilibrium phase diagram, the only crystalline phases present are elemental $\mathrm{Si}$ and the metastable $\mathrm{Li}_{15} \mathrm{Si}_{4}$ phase, ${ }^{2}$ underscoring the tendency to preferably form Li-rich phases during milling.

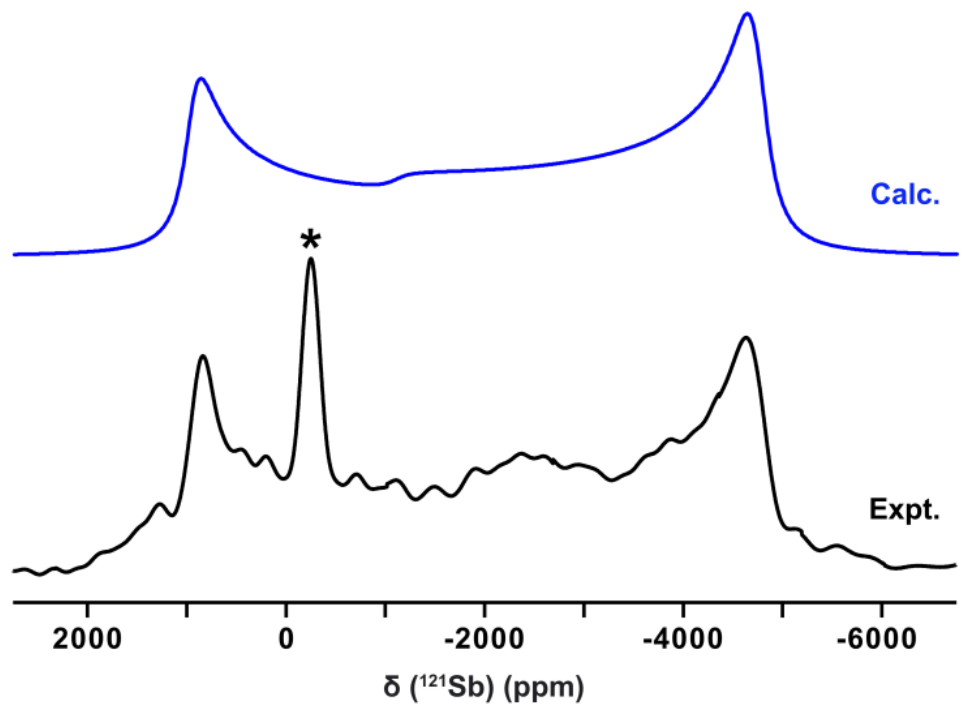

Figure S8. Non-spinning ${ }^{121} \mathrm{Sb}$ NMR spectrum (black) and simulation (blue) of $\mathrm{Li}_{2} \mathrm{Sb}\left(\mathrm{B}_{0}=11.7\right.$ $\mathrm{T} ; \mathrm{T}=293 \mathrm{~K}) .{ }^{*}$ refers to a $\mathrm{Li}_{3} \mathrm{Sb}$ impurity. 


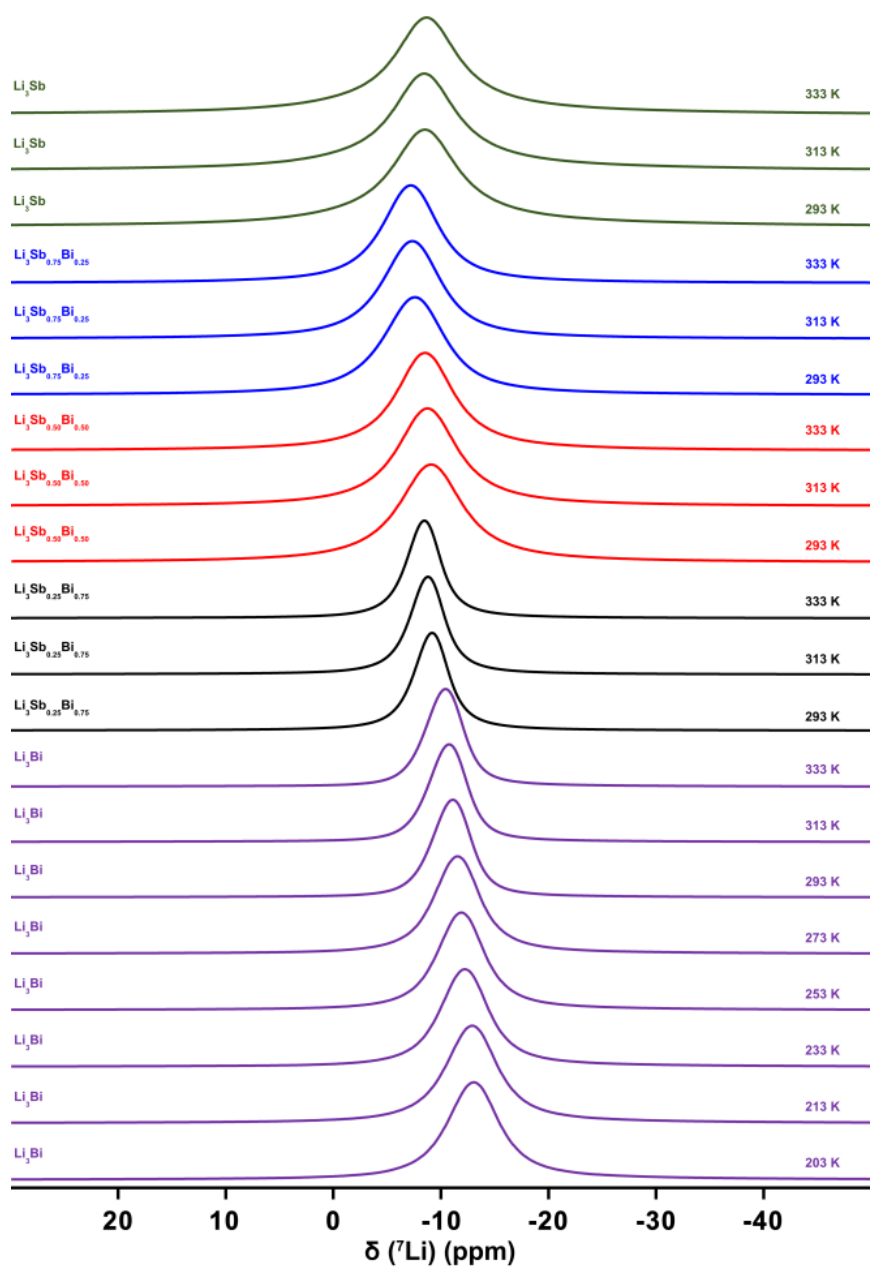

Figure S9. Non-spinning ${ }^{7} \mathrm{Li}$ variable temperature $\left(\mathrm{B}_{0}=11.75 \mathrm{~T}\right) \mathrm{NMR}$ of $\mathrm{Li}_{3} \mathrm{Sb}_{\mathrm{x}} \mathrm{Bi}_{1-\mathrm{x}}$ alloys.

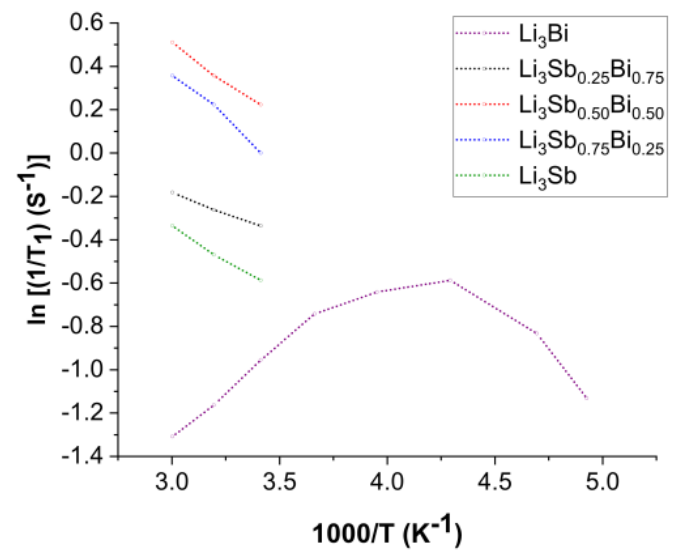

Figure S10. Temperature dependent ${ }^{7} \mathrm{Li}$ NMR nuclear spin-lattice relaxation rates $\left(1 / T_{1}\right)$ of the binary and ternary $\mathrm{Li}_{3}\left(\mathrm{Sb}_{\mathrm{x}} \mathrm{Bi}_{1-\mathrm{x}}\right)$ alloy series. 
Table S1. Summary of ${ }^{7} \mathrm{Li}$ MAS NMR and non-spinning ${ }^{7} \mathrm{Li},{ }^{121} \mathrm{Sb}$ and ${ }^{209} \mathrm{Bi}$ (non-spinning) NMR results for lithium alloyed compounds $\left(\mathrm{B}_{0}=11.7 \mathrm{~T}, \mathrm{~T}=293 \mathrm{~K}\right)$.

\begin{tabular}{|c|c|c|c|c|c|c|c|c|c|}
\hline \multirow[t]{2}{*}{ Compound } & \multirow[t]{2}{*}{$\begin{array}{l}\text { Space } \\
\text { group }\end{array}$} & \multicolumn{2}{|c|}{${ }^{7} \mathrm{Li}$ (MAS) } & \multicolumn{2}{|c|}{${ }^{7} \mathrm{Li}$ (non-spinning) } & \multicolumn{2}{|c|}{$\begin{array}{l}{ }^{121} \mathrm{Sb} \text { (non- } \\
\text { spinning) }\end{array}$} & \multicolumn{2}{|c|}{$\begin{array}{l}{ }^{209} \mathrm{Bi} \text { (non- } \\
\text { spinning) }\end{array}$} \\
\hline & & $\begin{array}{c}\delta_{\text {iso }} \\
( \pm 0.1) \\
(\mathrm{ppm})\end{array}$ & $\begin{array}{c}\text { FWHM } \\
( \pm 0.1) \\
(\mathrm{kHz})\end{array}$ & $\begin{array}{c}\delta_{\text {iso }} \\
( \pm 0.1) \\
(\mathrm{ppm})\end{array}$ & $\begin{array}{c}\text { FWHM } \\
( \pm 0.1) \\
(\mathrm{kHz})\end{array}$ & $\begin{array}{l}\delta_{\text {iso }} \\
( \pm 20) \\
(\mathrm{ppm})\end{array}$ & $\begin{array}{l}\text { FWHM } \\
( \pm 0.3) \\
(\mathrm{kHz})\end{array}$ & $\begin{array}{l}\delta_{\text {iso }} \\
( \pm 5) \\
(\mathrm{ppm})\end{array}$ & $\begin{array}{l}\text { FWHM } \\
( \pm 0.3) \\
(\mathrm{kHz})\end{array}$ \\
\hline $\mathrm{Li}_{3} \mathrm{Bi}$ & $F m \overline{3} m$ & -10.5 & 0.04 & -11.1 & 0.8 & NA & NA & -1790 & 14.3 \\
\hline $\mathrm{Li}_{3} \mathrm{Sb}_{0.25} \mathrm{Bi}_{0.75}$ & $F m \overline{3} m$ & $\begin{array}{l}-8.9 \\
-8.4\end{array}$ & 0.31 & -9.2 & 0.7 & -727 & 114.9 & NA & NA \\
\hline $\mathrm{Li}_{3} \mathrm{Sb}_{0.50} \mathrm{Bi}_{0.50}$ & $F m \overline{3} m$ & -8.8 & 0.41 & -9.0 & 1.4 & -967 & 114.8 & NA & NA \\
\hline $\mathrm{Li}_{3} \mathrm{Sb}_{0.75} \mathrm{Bi}_{0.25}$ & $F m \overline{3} m$ & -7.5 & 0.49 & -7.6 & 1.3 & -919 & 88.6 & NA & NA \\
\hline $\mathrm{Li}_{3} \mathrm{Sb}$ & $F m \overline{3} m$ & -7.3 & 0.34 & -8.5 & 1.5 & -496 & 15.4 & NA & NA \\
\hline
\end{tabular}


Table S2. Summary of ${ }^{7} \mathrm{Li}$ (non-spinning) center-of-gravity chemical shift, FWHM and $T_{1}$ NMR for lithium alloyed compounds at variable temperatures.

\begin{tabular}{|c|c|c|c|}
\hline $\begin{array}{l}\text { Temperature } \\
(\mathrm{K}, \pm 2)\end{array}$ & $\begin{array}{c}\delta_{\mathrm{cgs}} \\
(\mathrm{ppm} \pm 0.5)\end{array}$ & $\begin{array}{c}\text { FWHM } \\
(\mathrm{kHz} \pm 0.1)\end{array}$ & $\begin{array}{c}T_{1} \\
(\sec \pm 0.1)\end{array}$ \\
\hline \multicolumn{4}{|c|}{$\mathbf{L i}_{3} \mathbf{B i}$} \\
\hline 203 & -13 & 1.1 & 3.1 \\
\hline 213 & -12.8 & 1.1 & 2.3 \\
\hline 233 & -12.2 & 1.0 & 1.8 \\
\hline 253 & -11.8 & 1.0 & 1.9 \\
\hline 273 & -11.5 & 0.9 & 2.1 \\
\hline 293 & -11.1 & 0.8 & 2.6 \\
\hline 313 & -10.8 & 0.8 & 3.2 \\
\hline 333 & -10.4 & 0.8 & 3.7 \\
\hline \multicolumn{4}{|c|}{$\mathbf{L i}_{3} \mathbf{S b}_{0.25} \mathbf{B i}_{0.75}$} \\
\hline 293 & -9.2 & 0.7 & 1.4 \\
\hline 313 & -8.8 & 0.7 & 1.3 \\
\hline 333 & -8.5 & 0.7 & 1.2 \\
\hline \multicolumn{4}{|c|}{$\mathbf{L i}_{3} \mathbf{S b}_{0.50} \mathbf{B i}_{0.50}$} \\
\hline 293 & -9 & 1.4 & 0.8 \\
\hline 313 & -8.7 & 1.3 & 0.7 \\
\hline 333 & -8.4 & 1.2 & 0.6 \\
\hline \multicolumn{4}{|c|}{$\mathbf{L i}_{3} \mathbf{S b}_{0.75} \mathbf{B i}_{0.25}$} \\
\hline 293 & -7.6 & 1.3 & 1.0 \\
\hline 313 & -7.4 & 1.3 & 0.8 \\
\hline 333 & -7.2 & 1.2 & 0.7 \\
\hline \multicolumn{4}{|c|}{$\mathbf{L i}_{3} \mathbf{S b}$} \\
\hline 293 & -8.5 & 1.5 & 1.8 \\
\hline 313 & -8.5 & 1.5 & 1.6 \\
\hline 333 & -8.7 & 1.5 & 1.4 \\
\hline
\end{tabular}

\section{REFERENCES}

(1) Alloy Phase Diagram Database https://matdata.asminternational.org/apd/index.aspx (accessed Feb 12, 2019).

(2) Obrovac, M. N.; Christensen, L. Structural Changes in Silicon Anodes During Lithium Insertion/Extraction. Electrochem. Solid State Lett. 2004, 7, A93-A96. 